\title{
Removal of methylene blue from aqueous solution by mesoporous silicalite-1 synthetized using carboxymethyl cellulose as template
}

Sabarish Radoor ( $\sim$ sabarishchem@gmail.com )

King Mongkut's University of Technology North Bangkok https://orcid.org/0000-0002-0420-0240 Jasila Karayil

Government Women's Polytechnic College

Aswathy Jayakumar

King Mongkut's University of Technology North Bangkok

Jyothi Mannekote Shivanna

Dayananda Sagar College of Engineering

Jyotishkumar Parameswaranpillai

King Mongkut's University of Technology North Bangkok

Suchart Siengchin

King Mongkut's University of Technology North Bangkok

\section{Research Article}

Keywords: Mesoporous, Silicalite-1, Methylene blue, Adsorption, Kinetics

Posted Date: May 4th, 2021

DOI: https://doi.org/10.21203/rs.3.rs-350391/v2

License: (c) (i) This work is licensed under a Creative Commons Attribution 4.0 International License.

Read Full License 


\title{
Removal of methylene blue from aqueous solution by mesoporous silicalite-1 synthetized using carboxymethyl cellulose as template
}

\author{
Sabarish Radoor $^{1 *}$, Jasila Karayil ${ }^{2}$, Aswathy Jayakumar ${ }^{1}$, Jyothi Mannekote Shivanna ${ }^{3}$
} Jyotishkumar Parameswaranpillai ${ }^{1}$, Suchart Siengchin ${ }^{1 *}$

1. Materials and Production Engineering, The Sirindhorn International Thai-German Graduate School of Engineering (TGGS), King Mongkut's University of Technology North Bangkok, Bangkok 10800, Thailand

2. Government Women's Polytechnic College, Calicut, Kerala, India

3. Department of Chemistry, Dayananda Sagar College of Engineering, Shavige Malleshwara Hills, Kumaraswamy Layout, Bengaluru, 560078, India

*Corresponding authors:

Sabarish Radoor, Email: sabarishchem@gmail.com

Suchart Siengchin, Email: suchart.s.pe@tggs-bangkok.org

\section{Abstract}

In the present work, we have developed a mesoporous silicalite-1 using CMC as a template for the removal of $\mathrm{MB}$ from aqueous solution. The synthesized silicalite-1 were characterised using scanning electron microscopy (SEM), transmission electron microscopy (TEM), Fourier transform infrared spectroscopy (FT-IR), X-ray diffraction (XRD), thermogravimetric analysis (TGA), Energy-dispersive X-ray spectroscopy (EDX) and $\mathrm{N}_{2}$ adsorption-desorption isotherm (BET). XRD and FTIR analysis confirmed the formation of crystallinity and development of MFI structure in the mesoporous silicalite-1. The adsorption of MB dye on mesoporous silicalite-1 was conducted by batch adsorption method. The effect of various parameters such as adsorbent dosage, initial dye concentration, contact time and temperature on the dye uptake ability of silicalite-1 was investigated. The operating parameters for the maximum adsorption are silicalite-1 dosage $(0.1 \mathrm{wt} \%)$, contact time (240 $\mathrm{min})$, initial dye concentration (10 ppm) and temperature $\left(30^{\circ} \mathrm{C}\right)$. The $\mathrm{MB}$ dye removal onto mesoporous silicalite- 1 followed pseudosecond-order kinetic and Freundlich isotherm. The silicalite-1 exhibits $86 \%$ removal efficiency 
even after six adsorption-desorption cycle. Therefore, the developed mesoporous silicalite-1 is an effective eco-friendly adsorbent for MB dye removal from aqueous environment.

\section{Keywords: Mesoporous; Silicalite-1; Methylene blue; Adsorption; Kinetics}

\section{Introduction}

In the last few decades, the quality of water is declining in an alarming rate. Dyes are one of the major pollutants which deteriorate our water resources such as river, lake etc.[1-3] Synthetic dyes constitute about $90 \%$ of the total dye used in various industries such as paints, textiles, paper, printing, plastics and cosmetics [4-6]. Azo dye, anthraquinones dyes, phthalocyanines and polymethines are the common examples of synthetic dyes which is frequently employed for different application [7, 8]. Dye dissemination into water bodies is not only aesthetically unpleasant but also causes some major issues such as low dissolved oxygen (DO) level, high BOD level and obstruction for sunlight transmission through water[8-11]. Thus, it adversely affects the aquatic organism[11]. Dyes effluent also cause serious health risk to humans such as hypersensitivity, allergy, asthma, kidney dysfunction, liver and brain disorder [12-14]. Methylene blue (MB) are recalcitrant pollutant with cariogenic and mutagenic nature. It is generally used for dying cotton, silk and wool. The structural formula of MB is shown in figure 1. It causes several health issues such as eye burns, skin irritation, vomiting and nausea to humans [15-17].

The excessive use of dye raises concern and hence its removal from aqueous effluent has become a challenging topic for researchers and scientists. Researchers have designed several novel materials for dye removal by adopting technologies such as adsorption, coagulation, oxidation, filtration, ultrafiltration etc.[18-20]. Due to simplicity, low-cost and high efficiency, adsorption is considered as one of the most effective method for dye removal [21, 22]. Activated carbon and nanoparticle are effective adsorbent for dye removal applications, however due to high cost and low efficiency its large-scale usage is limited [23]. Recently, 
various low-cost and eco-friendly adsorbent were reported for removing dyes from wastewater including zeolites, kaolin, clay, montmorillonite, activated carbon, agricultural waste etc.[2328] Silicalite-1 belongs to family of zeolite and possesses aluminium free MFI type framework. High surface area and porous nature enable it to use in different application such as adsorption, catalyst and fine chemical industrial applications [29, 30].

Jing et al. [31] fabricated $\mathrm{TiO}_{2}$ loaded silicalite-1 for degradation of rhodamine $\mathrm{B}$. They reported that adsorbent dosage plays a key role in dye removal efficiency as they observed a significant increment in dye removal efficiency with adsorbent dosage. Cheng et al. [32] reported that $\mathrm{GO} /$ silicalite-1 composite is as an effective adsorbent for rhodamine $\mathrm{B}$. The maximum adsorption capacity $(56.55 \mathrm{mg} / \mathrm{g})$ was observed at $\mathrm{pH}=3$ within $30 \mathrm{~min}$ of contact time. Recently, our team fabricated sodium alginate modified silicalite-1 for rhodamine B removal. The modified silicalite-1 displayed high removal efficiency than conventional silicalite-1 probably due to the high surface area and pore diameter. The reusability test was also conducted to check the industrial advantage. The result proved that sodium alginate modified silicalite-1 exhibits good regeneration capacity [33].

There is only limited research available for dye adsorption studies on silicalite-1 from wastewater. So, in this work, we made an attempt to evaluate the dye (MB) adsorption capacity of s carboxymethyl cellulose (CMC) modified silicalite-1. The effect of different parameters such as initial dye concentration, contact time, temperature, dosage on the adsorption process was also discussed in details. The adsorption kinetics and isotherm on adsorption process is also presented.

\section{Materials and methods}

\section{Chemicals} tetraethylorthosilicate $\left(\mathrm{C}_{8} \mathrm{H}_{20} \mathrm{O}_{4} \mathrm{Si}\right.$; TEOS $)$ were purchased from Sigma Aldrich Co. Ltd 
81 (India). Carboxymethyl cellulose $\left(\left[\mathrm{C}_{6} \mathrm{H}_{7} \mathrm{O}_{2}(\mathrm{OH})_{\mathrm{x}}\left(\mathrm{OCH}_{2} \mathrm{COONa}\right)_{\mathrm{y}}\right]_{\mathrm{n}}, \mathrm{CMC}\right)$, and methylene

82

83

84

85

86

87

88

89

90

91

92

93

94

95

96

97

98

99

100

101

102

103

blue $\left(\mathrm{C}_{16} \mathrm{H}_{18} \mathrm{ClN} \mathrm{N}_{3} \mathrm{~S}, \mathrm{MB}\right)$ were purchased from Merck Co. Ltd (India). All the chemicals were used as such without further purification.<smiles>CN(C)c1ccc2nc3ccc(N(C)C)cc3[s+]c2c1</smiles>

Figure 1. Structural formula of methylene blue

\section{Synthesis of mesoporous silicalite-1}

The mesoporous silicalite-1 was synthesized by adopting hydrothermal method. In a typical synthesis, $3.49 \mathrm{~g}$ of tetra propylammonium hydroxide (TPAOH) and $3.1 \mathrm{~g}$ of tetraethyl orthosilicate (TEOS) were mixed in distilled water under constant stirring for $5 \mathrm{~h}$. After wards, $0.2 \mathrm{~g}$ of $\mathrm{CMC}$ is mixed to the above solution with constant stirring. The solution was concentrated in a rotavapor at $80{ }^{\circ} \mathrm{C}$ for $30 \mathrm{~min}$ to form a viscous solution. The resulting sol was introduced into a stainless autoclave for crystallisation at $80{ }^{\circ} \mathrm{C}$ for $24 \mathrm{~h}$ followed by high temperature treatment at $175^{\circ} \mathrm{C}$ for $8 \mathrm{~h}$. The obtained product was filtered, washed with water, dried and finally calcined at $550{ }^{\circ} \mathrm{C}$ for $5 \mathrm{~h}$ to remove the organic components. For comparison purpose, conventional silicalite-1 was prepared with similar procedure without adding template, CMC [34, 35]. 


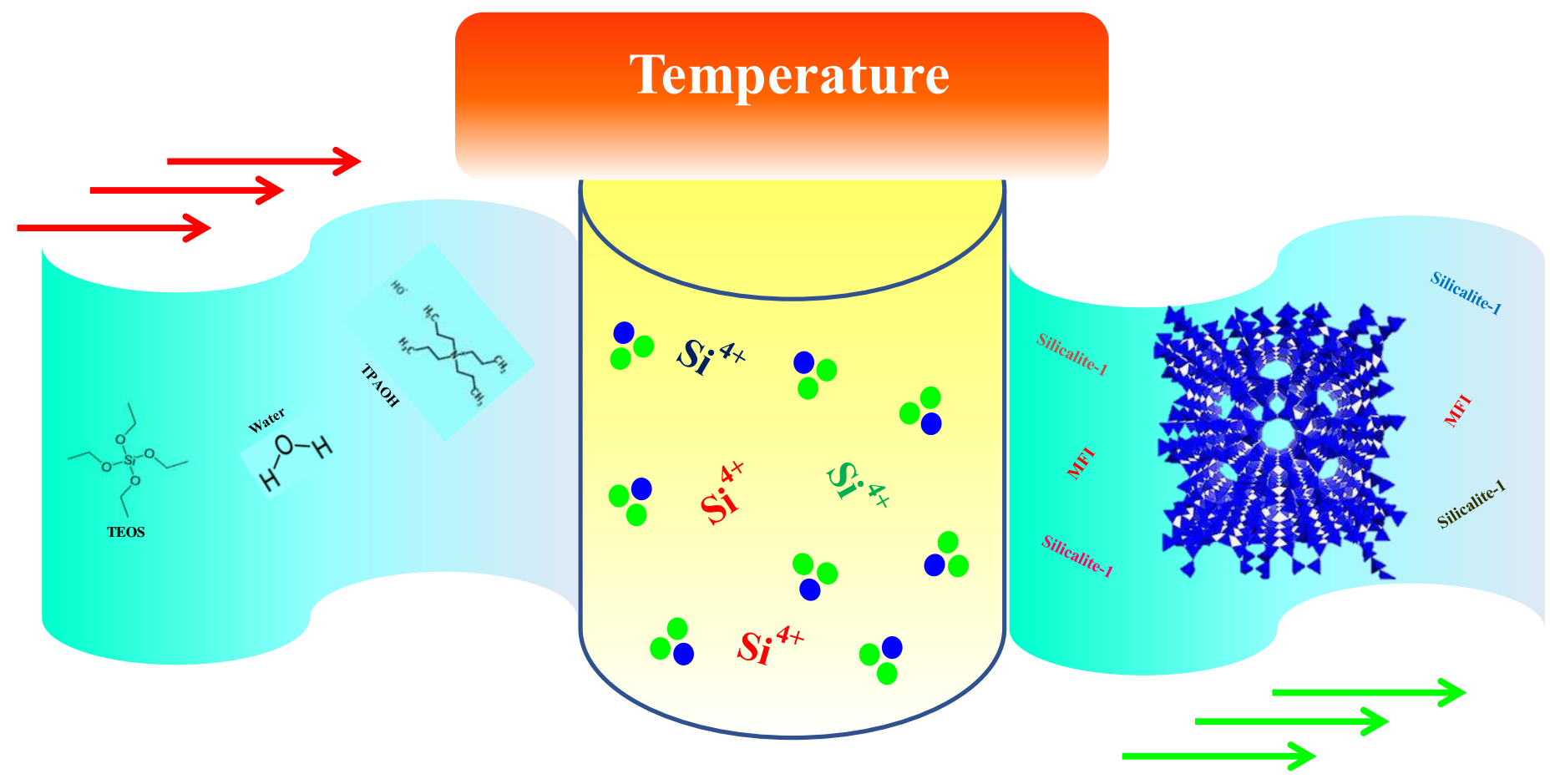

105

106 Scheme 1. Schematic diagram of silicalite-1

107 Characterization

108 Powder X-ray diffraction (XRD) patterns in the range of $5-50^{\circ}$ were obtained with a Rigaku

109 Miniflex 600 diffractometer using $\mathrm{CuK \alpha}$ radiation at a scanning speed of $4 \% \mathrm{~min}$. The

110 characteristic vibration bands were identified by Jasco 4700 FTIR spectrometer with $\mathrm{KBr}$

111 pellet. Scanning electron microscopic (SEM) images were recorded by using a Hitachi SU6600

112 Variable Pressure Field Emission Scanning Electron Microscope (SEM). Transmission

113 electron microscopic images (TEM) were taken with a JEOL JEM-2100 transmission electron

114 microscope operated at an accelerating voltage of $200 \mathrm{kV}$. The thermal stability of the

115 uncalcined sample was analysed by thermogravimetric (TG) analysis with Q50 instrument at a

116 heating rate of $10^{\circ} \mathrm{C} / \mathrm{min}$ in nitrogen atmosphere. $\mathrm{N}_{2}$ adsorption/desorption isotherm were

117 employed to find out the surface area and pore size distributions at $77 \mathrm{~K}$ with Micromeritics

118 Gemini V-2380 surface area analyser. Before measurement the sample was outgassed at 573K

119 for $3 \mathrm{~h}$. The $\mathrm{Si} / \mathrm{Al}$ ratio of the samples was determined by electron dispersive spectroscopy

120 (EDX) using JEOL JED-2300 instrument. 


\section{Adsorption experiment}

122

123

124

5

For adsorption studies, stock solution of MB (100 ppm) was prepared in distilled water. 10, 20, 30,40 and $50 \mathrm{ppm}$ of dye solution was prepared by diluting the stock solution. The $\mathrm{pH}$ of the dye solution was adjusted using $\mathrm{HCl}$ and $\mathrm{NaOH}$. The effect of the environmental parameters on dye removal was studied by varying adsorbent loading $(0.02-0.10 \mathrm{wt} \%)$, dye concentration $(10-50 \mathrm{ppm})$, contact time $(20-330 \mathrm{~min})$ and temperature $\left(30-60^{\circ} \mathrm{C}\right)$. Batch adsorption experiment was employed to find out the adsorption capacity of MB onto the mesoporous silicalite-1 sample. The dye uptake performance was assessed by soaking $0.10 \mathrm{wt} \%$ of silicalite-1 in $50 \mathrm{~mL}$ of $\mathrm{MB}$ dye at different temperature. After predetermined time intervals the sample was withdrawn, filtered and the solution was measured using UV-Vis spectrophotometer at $\lambda_{\max } \sim 668 \mathrm{~nm}$. From the calibration curve, the concentration of dye in the sample is noted. The experiments were done in triplicate and the average value is reported. The percentage removal and equilibrium concentration were calculated as follows

(1)

36

37

8

Where $\mathrm{C}_{0}$ and $\mathrm{C}_{\mathrm{e}}$ are the initial and equilibrium dye concentration $\left(\mathrm{mg} \mathrm{L}^{-1}\right), \mathrm{V}$ is the volume of dye solution $(\mathrm{L})$; and $\mathrm{W}$ is weight $(\mathrm{g})$ of the adsorbent.

\section{Desorption experiment}

Desorption experiment of MB on silicalite-1 was performed by immersing $0.10 \mathrm{wt} \%$ of mesoporous silicalite- 1 sample in $50 \mathrm{~mL}$ of $\mathrm{MB}$ solution $\left(10 \mathrm{ppm}\right.$, temperature- $\left.30^{\circ} \mathrm{C}\right)$. After complete equilibrium time, the silicalite- 1 was separated and eluted with $0.1 \mathrm{~mol} / \mathrm{L} \mathrm{HCl}$ to desorb the dye. The silicalite-1 was later washed with distilled water, dried and used for next cycle [36]. 


\section{Result and discussion}

147 Figure 2 shows the XRD patterns of conventional and mesoporous silicalite-1. Both silicalite-

1 exhibits typical MFI framework structure with five characteristic peaks at $7.98^{\circ}, 8.82^{\circ}, 23.18^{\circ}$, $24.02^{\circ}$ and $24.46^{\circ}$ corresponds to (101), (020), (503), (151) and (303) refection respectively. However, with the addition of template the peak intensity of silicalite- 1 slightly reduces, probably due to the development of mesopores. Thus, CMC template is efficient to generate mesoporosity in silicalite- 1 without compromising its crystallinity [35, 37]. To understand the chemical composition of membrane, we performed FTIR spectroscopy. The FTIR spectra of conventional and mesoporous silicalite-1 are displayed in Figure 3. The strong absorption band at $550 \mathrm{~cm}^{-1}$ is attributed to double five membraned ring which is characteristic of MFI framework. The band at $796 \mathrm{~cm}^{-1}$ and $1105 \mathrm{~cm}^{-1}$ are assigned to Si-O-Si external symmetric stretching $\left(\mathrm{SiO}_{4}\right.$ tetrahedra) and $\mathrm{Si}-\mathrm{O}-\mathrm{Si}$ internal asymmetric stretching $\left(\mathrm{SiO}_{4}\right.$ tetrahedra). The band at $1230 \mathrm{~cm}^{-1}$ is attributed to external asymmetric stretching of Si-O bond. A weak band observed at $1640 \mathrm{~cm}^{-1}$ could be due to the adsorbed water present in the sample. Finally, the absorption band at $462 \mathrm{~cm}^{-1}$ is due to Si-O-Si rocking. FTIR studies were thus complimentary to XRD study and confirmed the successful synthesis of silicalite-1 [33, 38].
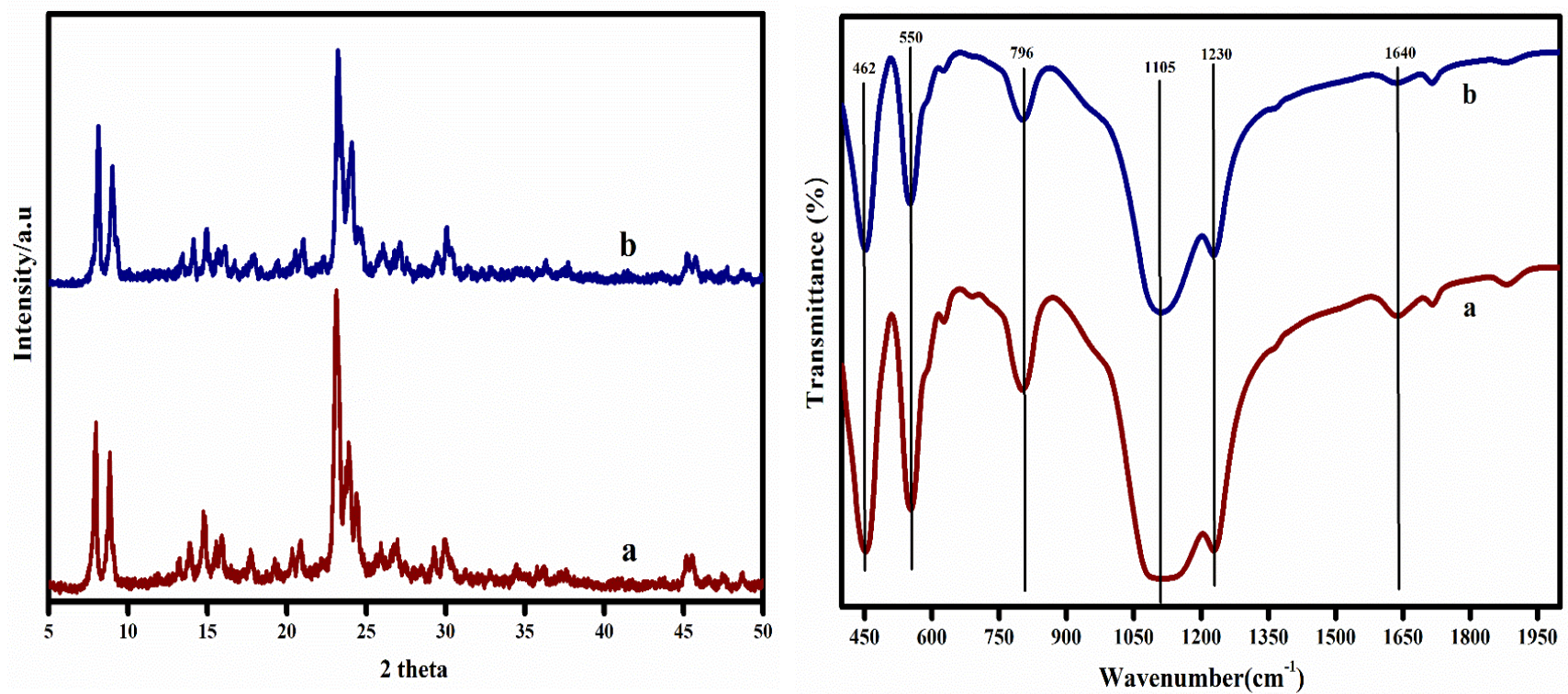

162 Figure 2. Powder XRD patterns and FTIR spectra of conventional and mesoporous silicalite- 
The morphology of conventional and mesoporous silicalite-1 was evaluated by SEM and TEM analysis (Figure 3 and 4). The SEM image of mesoporous silicalite-1 (Figure 3) shows a rough surface with sphere like particle in the range of $10-30 \mathrm{~nm}$. The result thus suggests the formation of mesopore in the system, which is attributed to the removal of templates. TEM images further confirmed that mesoporous silicalite-1 have pore diameter in the range of 10$30 \mathrm{~nm}$. The prominent lattice fringes seen in the TEM images imply a high crystallinity for the sample and are complementary to the previous reported work [39] (Figure. 4). The elemental composition of mesoporous silicalite-1 is detected using EDAX measurement. The analysis indicates that the synthesized sample contains only $\mathrm{Si}$ and $\mathrm{O}$, thus confirming the product is silicalite-1. $\mathrm{N}_{2}$ adsorption/desorption isotherm were employed to characterize the surface area and porosity of the sample. Figure 5(I) illustrates the $\mathrm{N}_{2}$ adsorption/desorption isotherm of conventional and mesoporous silicalite-1. As shown in Figure 5a, the conventional silicalite-1 belongs to type 1 isotherm with major uptake of gas at a relative low pressure $(\mathrm{P} / \mathrm{Po}<0.2)$. This indicates the presence of only micropores in the system. However, mesoporous silicalite-1 exhibits a prominent hysteresis loop at $\mathrm{P} / \mathrm{Po}=0.25$ to 0.9 due to the capillary condensation of nitrogen. The result thus indicates the co-existence of micro and mesopores in the modified sample. BJH (Barrett-Joyner-Halenda) pore size distribution is shown in Figure 5(II). It is templated sample. 


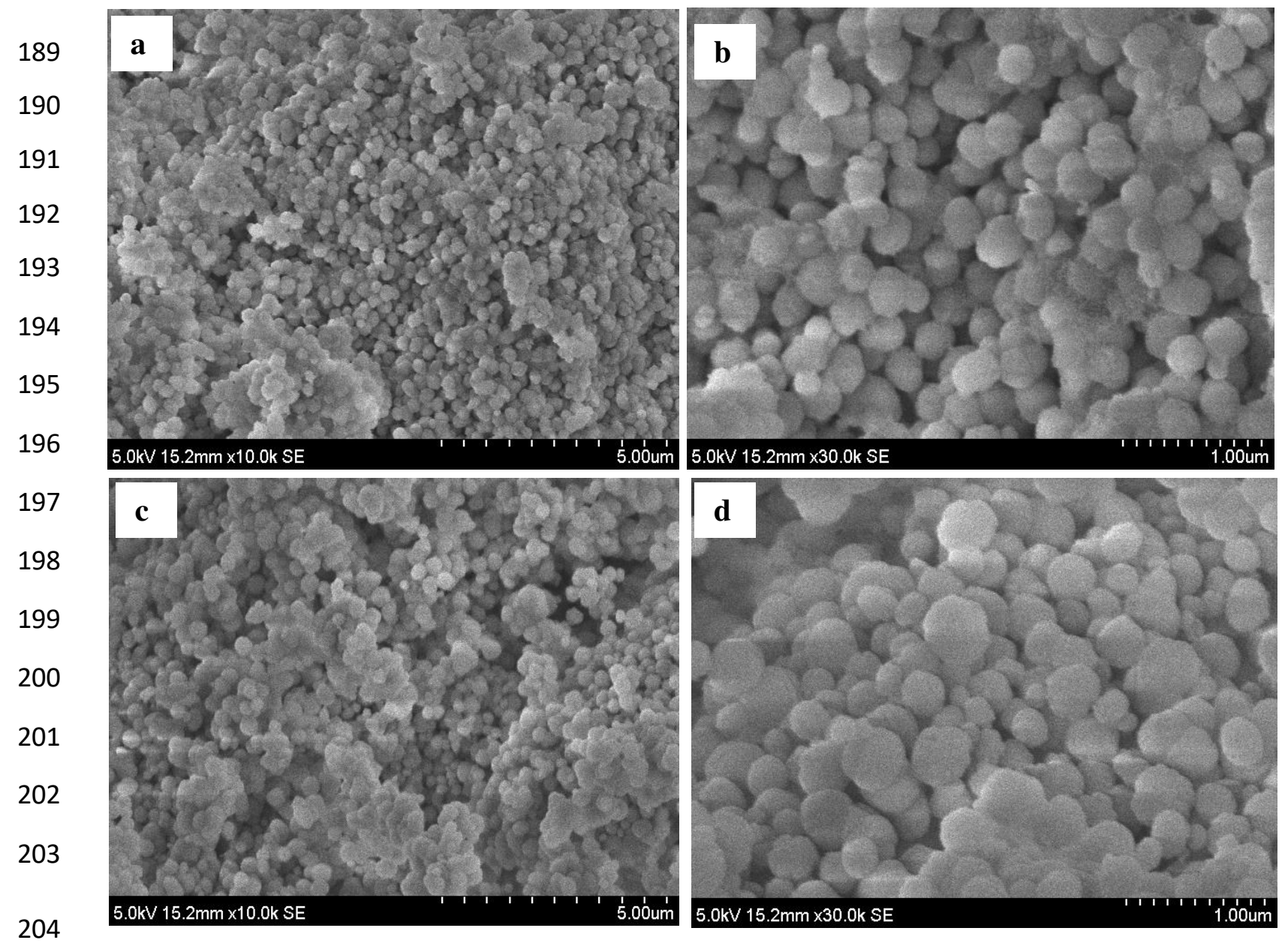

205 Figure 3. SEM micrographs of (a \& b) conventional and (c \& d) mesoporous silicalite-1

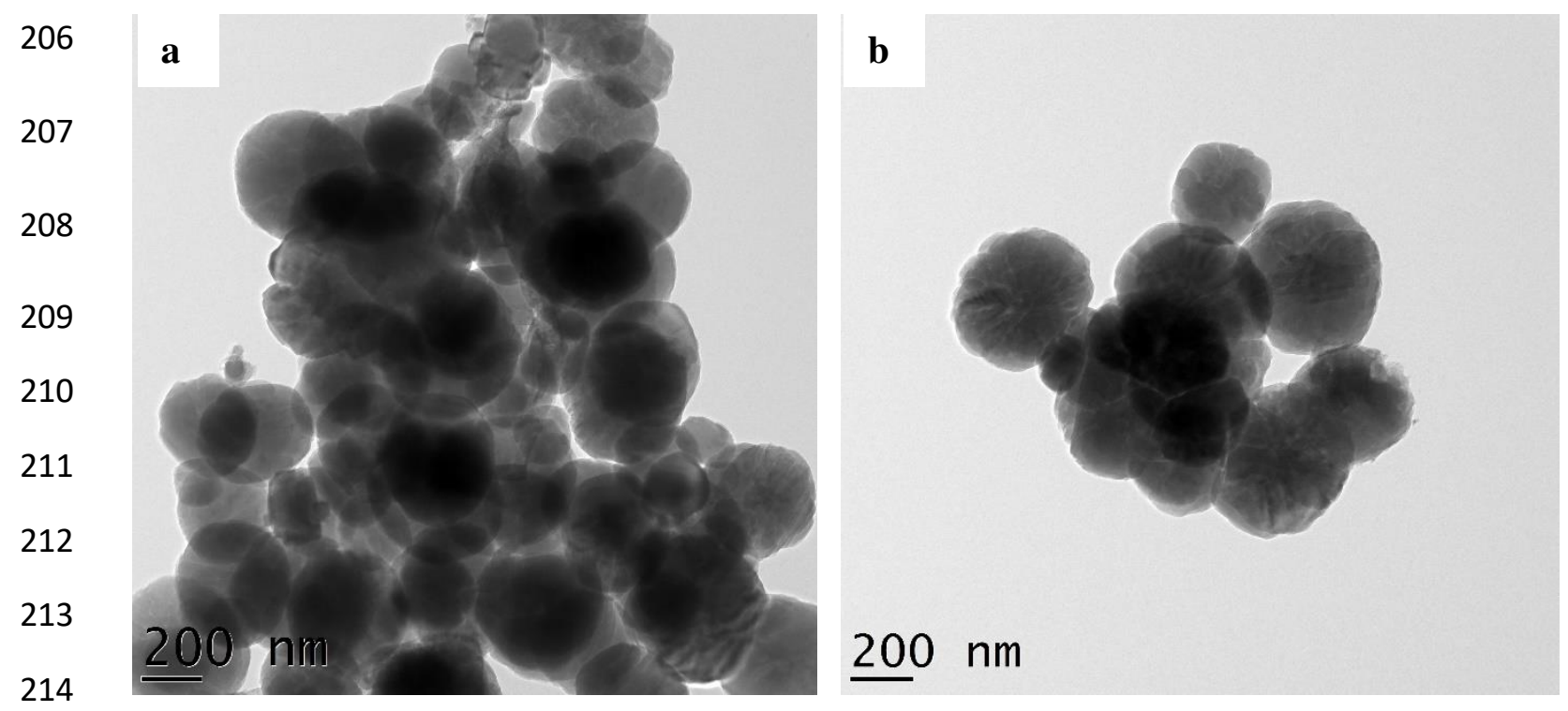

215

216 Figure 4. TEM images of mesoporous silicalite-1 

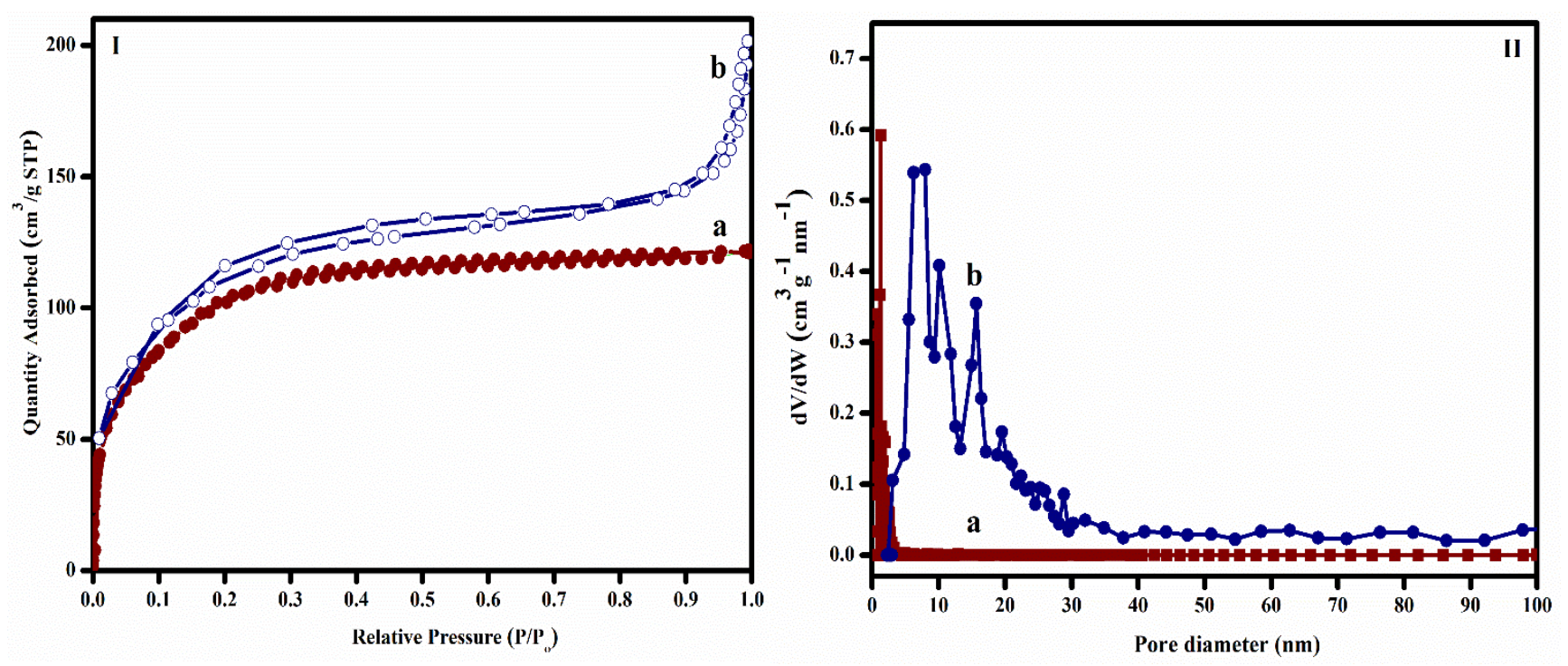

217

218 Figure 5. (I) $\mathrm{N}_{2}$ adsorption isotherms of: a) conventional b) mesoporous silicalite-1; (II) pore 219 size distribution of: a) conventional b) mesoporous silicalite-1

220 The thermal stability of conventional and mesoporous silicalite-1 is compared by 221 thermogravimetric analysis (Figure 6). The conventional silicalite-1 showed $16 \%$ of total 222 weight loss at $100-250^{\circ} \mathrm{C}$ and $300-500^{\circ} \mathrm{C}$. This is attributed to the loss of water and $\mathrm{TPAOH}$

223 respectively from the silicalite-1 framework. In the case of mesopores silicalite-1, a third 224 weight loss appears at $500^{\circ} \mathrm{C}$ which is due to the decomposition of template. As modified 225 silicate possess higher weight loss (22\%) than conventional silicalite-1, it is thermally more 226 stable than conventional silicalite-1. 

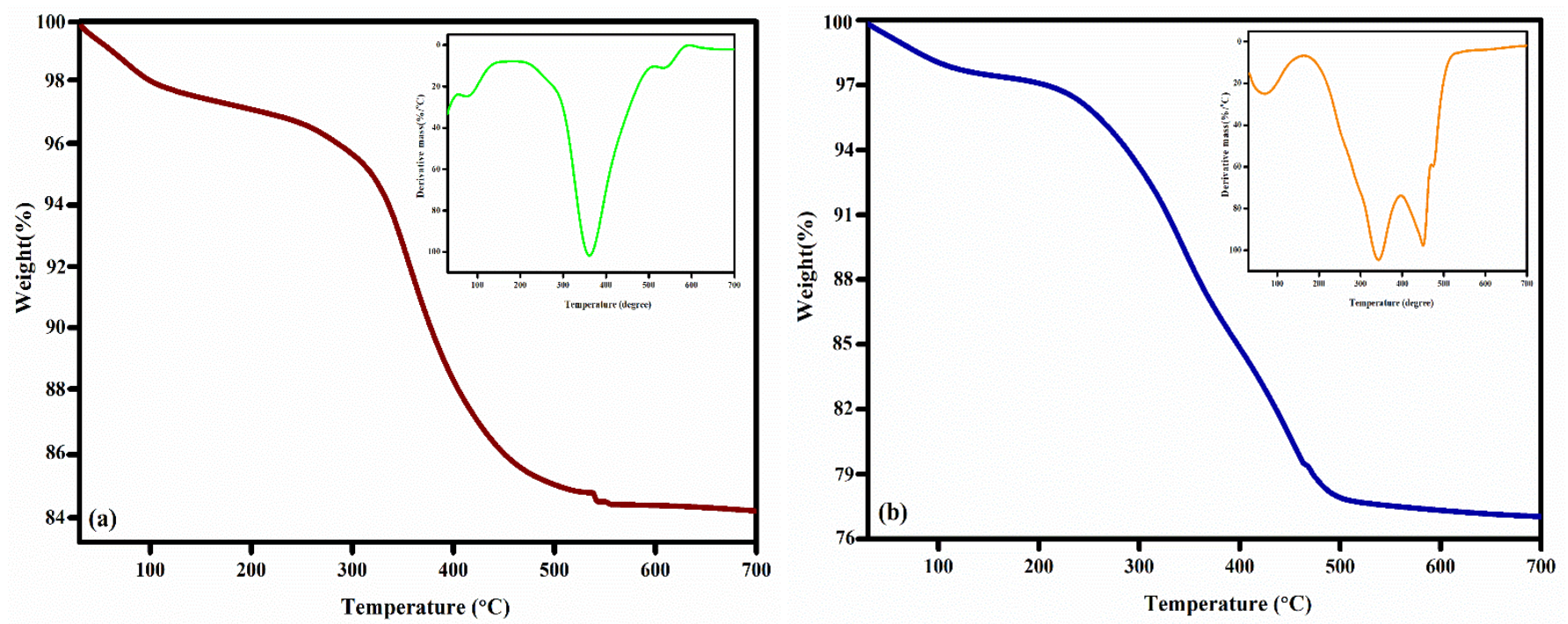

Figure 6. TGA curves of conventional and mesoporous silicalite-1 and the corresponding DTG curves are given at the inset

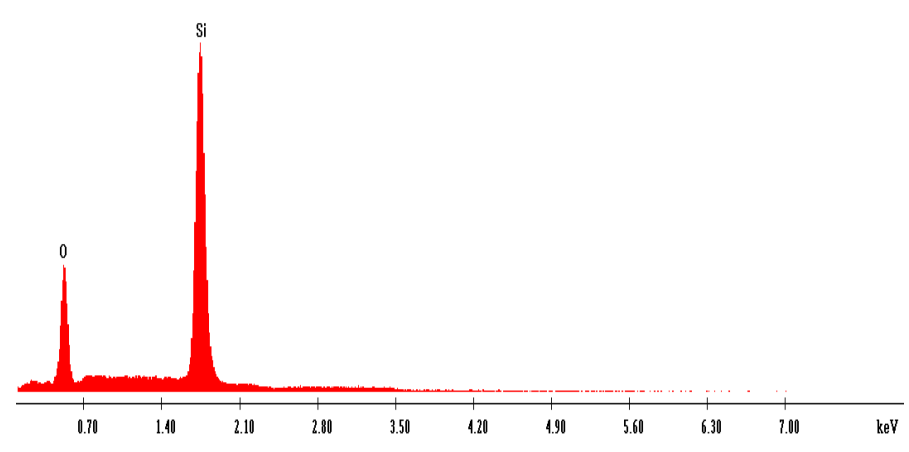

Figure 7. EDS image of mesoporous silicalite-1

\section{Adsorption experiment of mesoporous silicalite-1 on methylene blue}

Due to the presence of micro and mesoporous structure, modified silicalite- 1 is expected to have good adsorption capacity for dye molecule. This prompted us to monitored the dye (MB) uptake ability of modified silicate. The influence of environmental parameters such as silicalite-1 dosage, temperature, initial dye concentration and contact time was also investigated in detail. The influence of silicate dosage on the MB removal was carried out by varying the silicalite- 1 from 0.02 to $0.10 \mathrm{wt} \%$. From Figure $8(\mathrm{a})$, it can clearly see that the dye adsorption capacity increases linearly with adsorbent dosage. High surface area along with the 
presence of micro/mesoporous structure on silicalite- 1 could have increases the affinity of dye molecule to the adsorbent. Consequently, adsorption capacity increases and a maximum adsorption capacity $(4 \mathrm{mg} / \mathrm{g})$ was achieved at $0.10 \mathrm{wt} \%$ of adsorption dosage. The relationship between initial dye concentration and adsorption capacity of MB is shown in Figure $8(\mathrm{~b})$. It is evident from figure that when the initial dye concentration increases from 10 to $50 \mathrm{ppm}$, the adsorption capacity increases from 4 to $16.45 \mathrm{mg} / \mathrm{g}$. Similar results have also been reported by Duman et al [40]. They observed that on increasing the initial dye concentration from 20 to 40 $\mathrm{mg} / \mathrm{L}$ the adsorption capacity increases from 8 to $15 \mathrm{mg} / \mathrm{g}$. Dong et al. [41] reported that mesoporous SBA-15 exhibits high adsorption capacity when the initial concentration exceeds $230 \mathrm{mg} / \mathrm{g}$. According to the authors high initial concentration provides a necessary driving force for the diffusion of dye from aqueous to the solid phase. We have varied the immersing time from 10-330 min and evaluate its effect on the MB adsorption was in the following operational conditions initial dye concentration $-10 \mathrm{ppm}$, temperature- $30^{\circ} \mathrm{C}$ and dosage- -0.1 $\mathrm{wt} \%$. In the initial contact time, due to availability of large number of unoccupied active sites on the surface of adsorbent, the rate of adsorption increases, Therefore, adsorption capacity steeply rises in the initial phase of contact time. However, the rate of adsorption becomes gradual $120 \mathrm{~min}$ and eventually at $240 \mathrm{~min}$ it reaches constant. This implies that the adsorption from 4 to $7 \mathrm{mg} / \mathrm{g}$, thus suggesting that the MB adsorption on silicalite-1 is endothermic. High temperature tends to enhances the mobility of dye molecule. As a result, the dye molecule can 
271 favours the MB adsorption on silicalite-1. Scheme 2 show the schematic representation of

272 mesoporous silicalite-1 will interact with MB dye molecule.

273
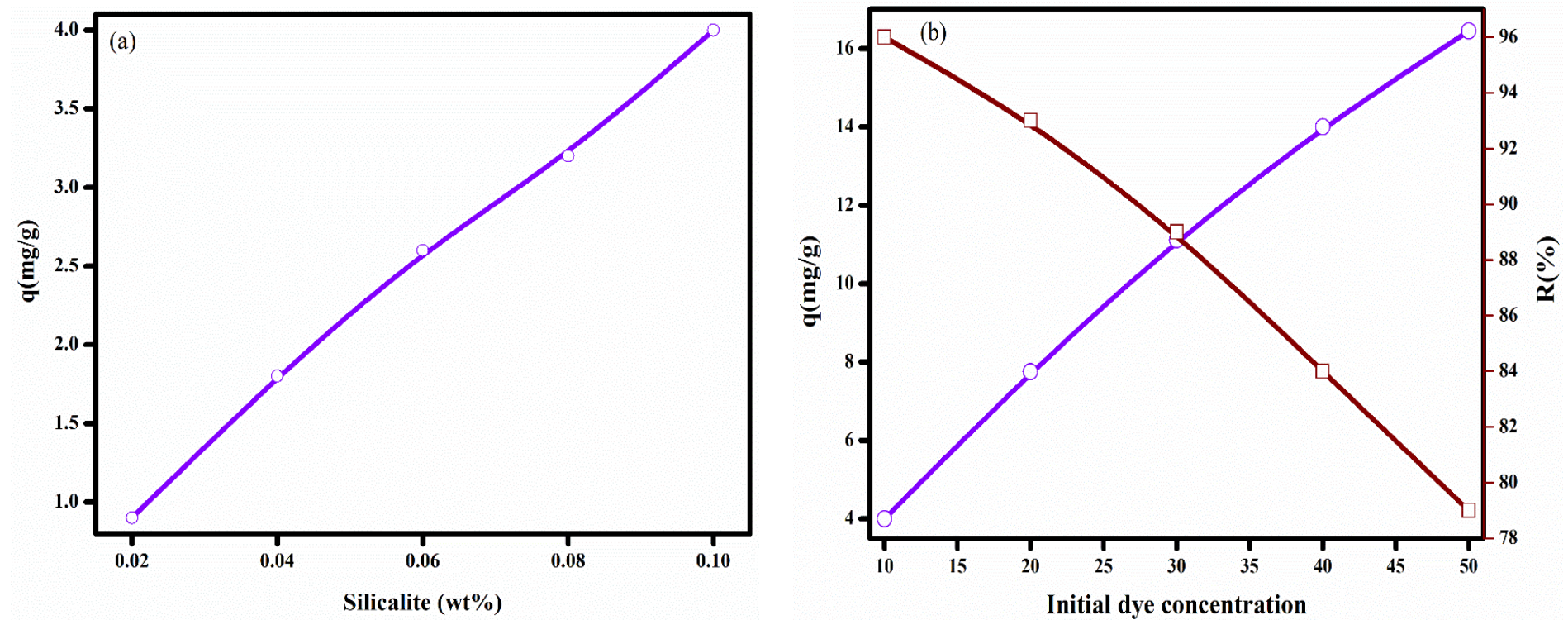

274
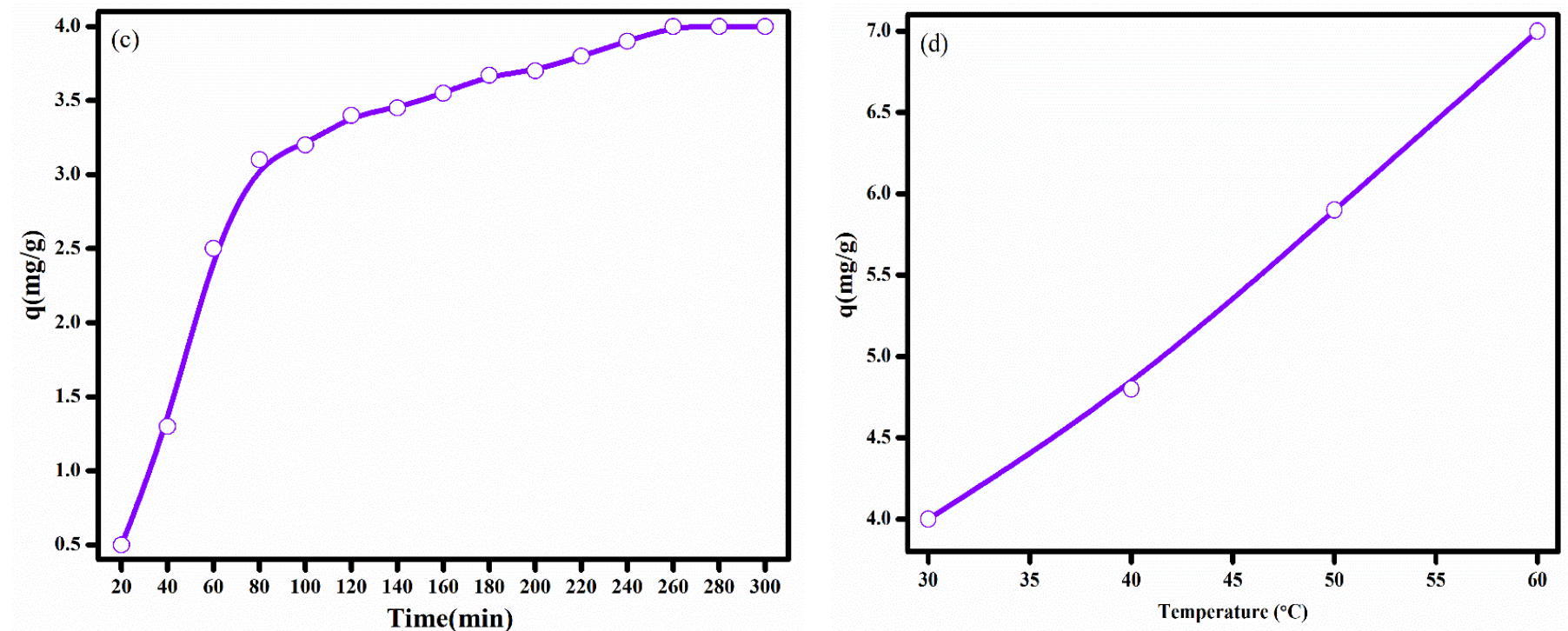

275 Figure 8. Effect of various parameters on the adsorption of MB onto mesoporous silicalite-1

276 a) silicalite-1 dosage b) initial dye concentration c) contact time d) temperature on the

277 adsorption process (adsorbent dosage $=0.10 \mathrm{wt} \%$, initial $\mathrm{MO}$ concentration $=10 \mathrm{ppm}$, contact

278 time $=240 \mathrm{~min}$ and temperature $=30^{\circ} \mathrm{C}$ 


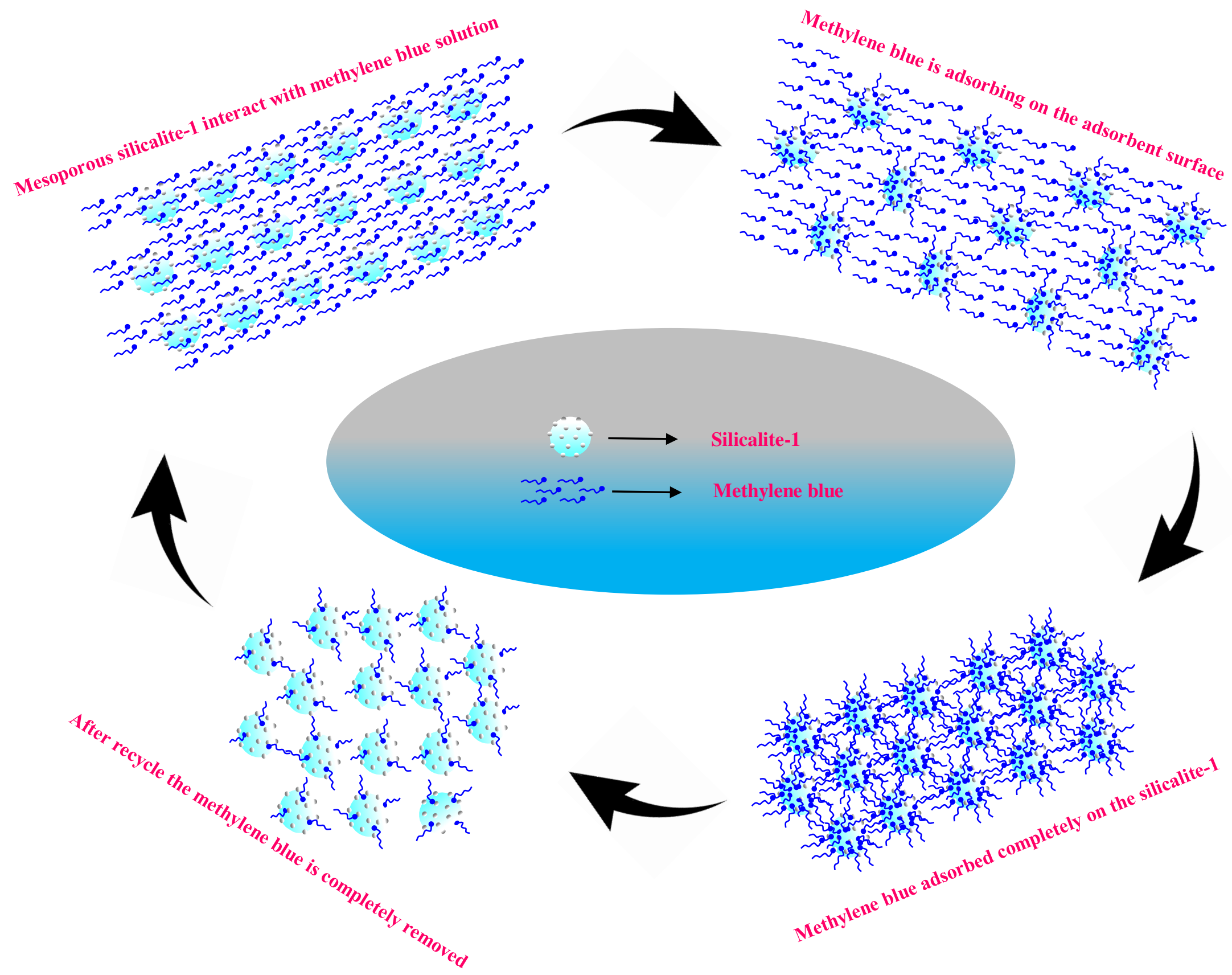

Scheme 2. Mechanism for MB adsorption on mesoporous silicalite-1 


\section{Adsorption kinetics}

2 Adsorption kinetics was investigated to understand the adsorption mechanism and rate of

3 adsorption of MB dye onto adsorbent. The experimental data was evaluated using two well-

4 known models; pseudo-first-order and pseudo-second-order model. The linearized form of

5 pseudo-first-order kinetic equation is expressed as follows [43]

6

7 where $\mathrm{q}_{\mathrm{t}}(\mathrm{mg} / \mathrm{g})$ and $\mathrm{q}_{\mathrm{e}}(\mathrm{mg} / \mathrm{g})$ are the amount of dye adsorbed at time ' $\mathrm{t}$ ' and equilibrium. $\mathrm{K}_{1}$

8 are pseudo-first-order rate constant in $1 /$ min. The graph of $\log \left(q_{e}-q_{t}\right)$ vs. $t$ gives a straight

$9 \quad$ with $\mathrm{k}_{1}$ as slope and $\mathrm{q}_{\mathrm{e}}$ as intercept.

The pseudo-second-order model is as follow[44]

$$
\frac{t}{q_{e}}=\frac{1}{K_{2} q_{e}^{2}}+\frac{t}{q_{e}}
$$

where $\mathrm{K}_{2}$ is pseudo-second-order rate constant ( $\mathrm{g} / \mathrm{mg} \min$ ) and $\mathrm{q}_{\mathrm{e}}$ is equilibrium adsorption capacity. The value of $\mathrm{q}_{\mathrm{e}}$ and $\mathrm{K}_{2}$ were obtained from the slope and intercept of plot $\mathrm{t} / \mathrm{q}_{\mathrm{t}} \mathrm{vs} t$.

The experimental data fitting on the kinetic model is illustrated in Figure 9 and the corresponding kinetic data are presented in Table 1. the validity of these models was checked by noting the correlation coefficient value $\left(\mathrm{R}^{2}\right)$. As can be seen, the experimental value fitted well in pseudo-second-order (0.99) model than pseudo-first-order (0.95). In addition to this, the correlation coefficient of pseudo-second-order model is higher than pseudo-first-order model. Therefore, pseudo-second-order is more suitable than pseudo-first order to explain kinetics of MB uptake on silicalite-1. 

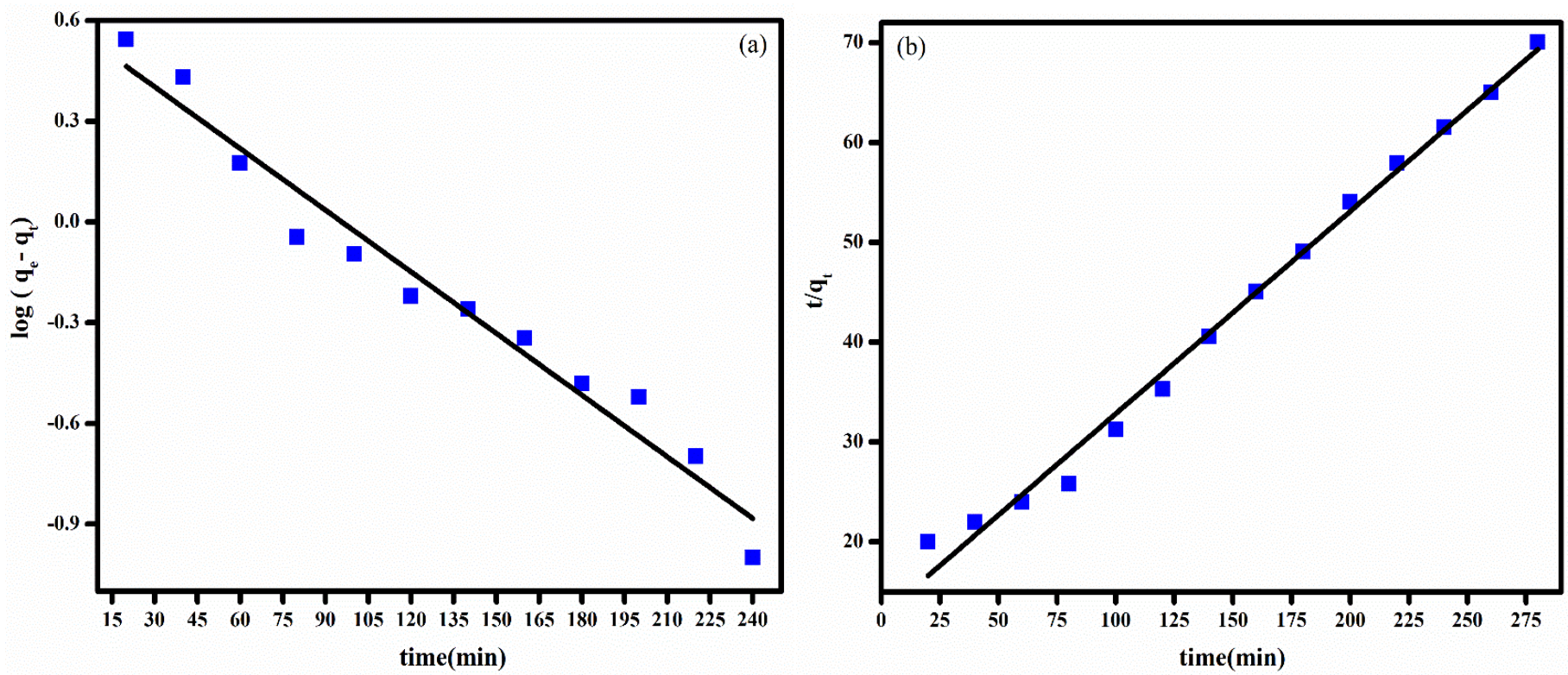

Figure 9. a) pseudo-first-order b) pseudo-second-order models for the adsorption of MB dye onto mesoporous silicalite-1

Table 1. Kinetic parameter values of adsorption kinetics for MB onto mesoporous silicalite-1

\begin{tabular}{ccccccc}
\hline Experimental & \multicolumn{3}{c}{ PFO } & PSO & \\
\hline $\mathrm{q}_{\mathrm{e}}, \exp \left(\mathrm{mg} \mathrm{g}^{-1}\right)$ & $\mathrm{K}_{1}\left(\mathrm{~min}^{-1}\right)$ & $\mathrm{qe}_{\mathrm{e}}\left(\mathrm{mg} \mathrm{g}^{-1}\right)$ & $\mathrm{R}^{2}$ & $\mathrm{~K}_{2}\left(\mathrm{~g} \mathrm{mg}^{-1} \mathrm{~min}^{-1}\right)$ & $\mathrm{qe}_{\mathrm{e}}\left(\mathrm{mg} \mathrm{g}^{-1}\right)$ & $\mathrm{R}^{2}$ \\
\hline 4 & -0.0140 & 3.2 & 0.95 & 0.0031 & 3.95 & 0.99
\end{tabular}

\section{Adsorption isotherm}

31 Adsorption isotherm is essential to understand the adsorption behaviour and interaction

32 between the adsorbate and adsorbent. The linear form of Langmuir model is expressed as

33 follows[45, 46]

$$
\frac{\mathrm{C}_{\mathrm{e}}}{\mathbf{q}_{\mathrm{e}}}=\frac{\mathrm{C}_{\mathrm{e}}}{\mathbf{q}_{\max }}+\frac{1}{\mathbf{K}_{\mathrm{L}} \mathbf{q}_{\max }}
$$

35 where $\mathrm{q}_{\mathrm{e}}$ is the amount of $\mathrm{MB}$ dye adsorbed at equilibrium, $\mathrm{C}_{\mathrm{e}}$ is the equilibrium concentration 36 of $\mathrm{MB}$ dye $(\mathrm{mg} / \mathrm{L}), \mathrm{q}_{\max }$ is maximum adsorption capacity, $\mathrm{K}_{\mathrm{L}}$ and $\mathrm{R}_{\mathrm{L}}$ are characteristic 37 Langmuir parameters which is termed as Langmuir adsorption constant and separation factor 38 respectively. $R_{L}$ is expressed as 


$$
R_{L}=\frac{1}{1+K_{L} C_{0}}
$$

41 Here, $\mathrm{C}_{\mathrm{o}}$ is initial MB concentration $(\mathrm{mg} / \mathrm{L})$. The value of $\mathrm{RL}$ is significant and is related to the

42 feasibility of adsorption. The adsorption process is favorable, if RL is between 0 and 1 , unfavorable if $\mathrm{R}_{\mathrm{L}}>1 . \mathrm{R}_{\mathrm{L}}=0$ and $\mathrm{R}_{\mathrm{L}}=1$ indicates reversible and linear adsorption respectively

44 [52].

The Langmuir isotherm model assumes a homogeneous surface with equivalent site. According to this model, there is no interaction between the adsorbed molecules and hence multilayer adsorption will not occur. From the linear plot of $\mathrm{C}_{\mathrm{e}} / \mathrm{q}_{\mathrm{e}}$ vs. $\mathrm{C}_{\mathrm{e}}$, the value of $\mathrm{q}_{\mathrm{e}}$ and $\mathrm{K}_{\mathrm{L}}$ is obtained. The Freundlich isotherm on the other hand assume heterogeneous surface and there is no restriction of multilayer formation. Therefore, in this model both monolayer and multilayer adsorption can take place. The linearized form of Freundlich model is represented as [47]

$$
\operatorname{In} \mathrm{q}_{\mathrm{e}}=\frac{1}{\mathrm{n}} \operatorname{In} \mathrm{C}_{\mathrm{e}}+\operatorname{In}
$$

Where $\mathrm{K}_{\mathrm{F}}$ and $\mathrm{n}$ are Freundlich constants related to adsorption capacity and degree of adsorption respectively. The value of $\mathrm{K}_{\mathrm{F}}$ and $\mathrm{n}$ can be determined from the plot of $\ln \mathrm{q}_{\mathrm{e}} \mathrm{vs}$. $\ln$ $\mathrm{C}_{\mathrm{e}}$.

The data of adsorption process were applied to Langmuir and Freundlich isotherm model and the adsorption parameters are shown in Table 2. Since Freundlich isotherm gives a better fit with high correlation coefficient $\left(\mathrm{R}^{2}\right)$ it could be more suitable for $\mathrm{MB}$ adsorption. The value of $1 / \mathrm{n}$ is between 0 and 1 indicating that the MB adsorption on mesoporous silicalite- 1 is a favourable process. 

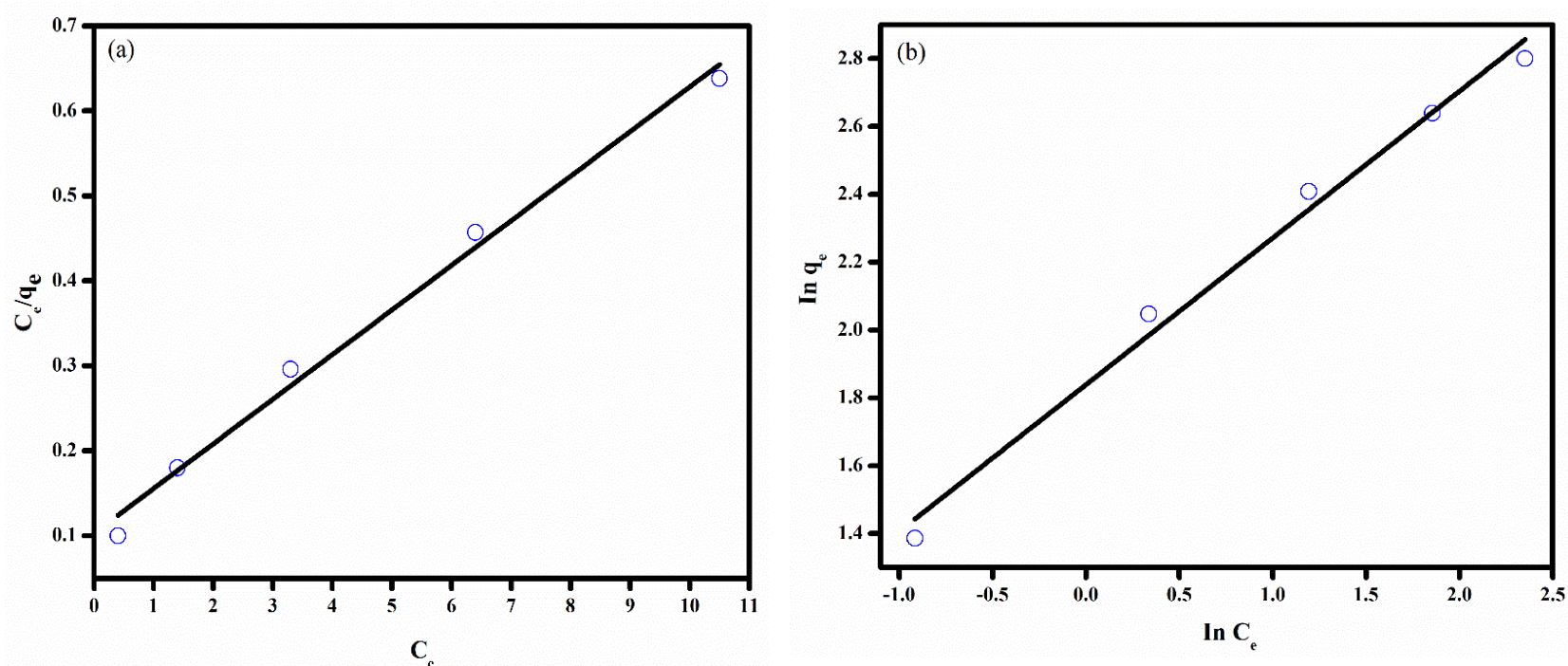

Figure 10. Isotherm model plots for the adsorption of MB a) Langmuir isotherm b) Freundlich 61 isotherm

Table 2. Langmuir isotherm and Freundlich isotherm parameter values for MB adsorption onto 64 mesoporous silicalite-1

\begin{tabular}{lllllll}
\hline Experimental & \multicolumn{3}{c}{ Langmuir isotherm } & \multicolumn{3}{c}{ Freundlich isotherm } \\
\hline $\mathrm{q}_{\mathrm{e}}, \exp \left(\mathrm{mg} \mathrm{g}^{-1}\right)$ & $\mathrm{R}^{2}$ & $\mathrm{q}_{\max }\left(\mathrm{mg} \mathrm{g}^{-1}\right)$ & $\mathrm{K}_{\mathrm{L}}$ & $\mathrm{R}^{2}$ & $\mathrm{~K}_{\mathrm{F}}\left(\mathrm{mg} \mathrm{g}^{-1}\right)$ & $\mathrm{n}$ \\
\hline 4 & 0.977 & 19.04 & 0.509 & 0.995 & 4.3 & 2.31 \\
\hline
\end{tabular}

65

66 Recyclability

67 The regeneration performance of the modified silicalite-1 was studied by six adsorption-desorption cycles at fixed adsorbent dose of $0.10 \mathrm{wt} \%$ and initial dye concentration $10 \mathrm{ppm}$. The result is presented in Figure 11. The result shows that the removal percentage of membrane at the first adsorption-desorption cycle is $95 \%$ and after six adsorption-desorption cycles, the adsorption efficiency was reduced to $86.3 \%$. The results thus demonstrate that the silicalite-1 is effective even after multiple reuses. 


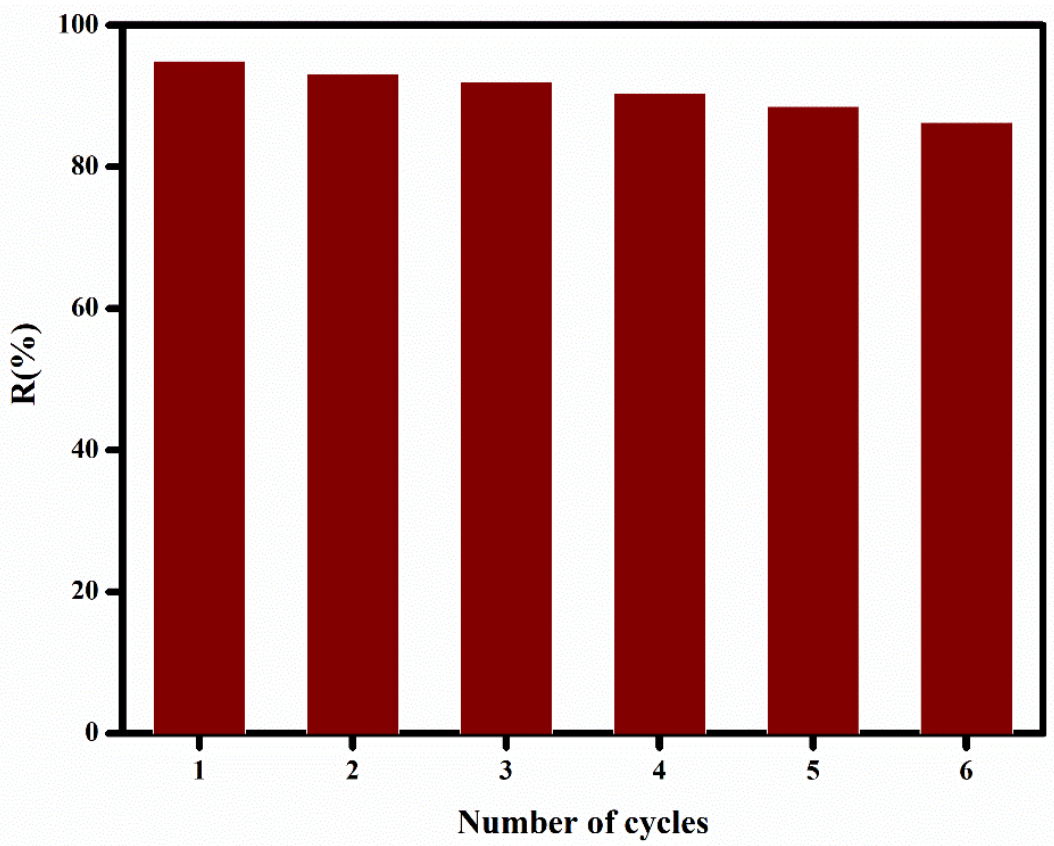

Figure 11. Reusability performance of adsorption of MB onto mesoporous silicalite-1

\section{Conclusion}

In the present study, a mesoporous silicalite-1 was developed using eco-friendly template, CMC. The successful synthesis of modified silicate was confirmed by techniques such as SEM, TEM, $\mathrm{N}_{2}$ isotherm, XRD, FTIR. The synthesized mesoporous silicalite-1was effective to remove the cationic dye methylene blue from water. The effect of various operational parameter on the dye adsorption was studied and the result indicate that adsorption is favored at high initial concentration, high immersing time and high temperature. The dye removal was found to be governed by Freundlich isotherm model and the rate of adsorption was found to obey pseudo-second-order kinetics. The mesoporous silicalite-1 sample also show excellent recyclability. Therefore, we can conclude that modified silicalite-1 is a highly attractive candidate for the removal of MB from water.

\section{Consent for publication}

The authors confirm the consent for publication

\section{Availability of data and material}

All data generated or analysed during this study are included in this published article 


\section{Funding}

(Grant No. KMUTNB-63-Post-03 to SR) and (Grant No. KMUTNB-64-03, KMUTNBBasicR-64-16)

\section{Authors contribution}

Sabarish Radoor- Conceptualization, Methodology, Investigation, Validation, Writing original draft, Software, Writing - review \&editing, Formal analysis; Jasila Karayil Investigation, Analysis, Interpretation of results, Software, Writing - review \& editing, Formal analysis.; Aswathy Jayakumar - Data collection, Validation, Writing - review \& editing, Formal analysis; Jyothi Mannekote Shivanna - Interpretation of results, Software, Writing review \& editing, Jyotishkumar Parameswaranpillai -Validation, Software, Writing - review \& editing and Investigation; Suchart Siengchin - Editing, Funding and Supervision

\section{Acknowledgements}

The study was financially supported by the King Mongkut's University of Technology North Bangkok (KMUTNB), Thailand through the Post-Doctoral Program (Grant No. KMUTNB63-Post-03 and KMUTNB-64-Post-03 to SR) and (Grant No. KMUTNB-BasicR-64-16)

\section{Compliance with ethical standards}

Conflict of interest: The authors have declared no conflict of interest

\section{References}

[1] S. Wang, E. Ariyanto, Competitive adsorption of malachite green and $\mathrm{Pb}$ ions on natural zeolite, Journal of Colloid and Interface Science, 314 (2007) 25-31.

[2] X.S. Wang, Y. Zhou, Y. Jiang, C. Sun, The removal of basic dyes from aqueous solutions using agricultural by-products, Journal of Hazardous Materials, 157 (2008) 374-385.

[3] S. Radoor, J. Karayil, J. Parameswaranpillai, S. Siengchin, Removal of anionic dye Congo red from aqueous environment using polyvinyl alcohol/sodium alginate/ZSM-5 zeolite membrane, Scientific Reports, 10 (2020).

[4] V.K. Gupta, Suhas, Application of low-cost adsorbents for dye removal - A review, Journal of Environmental Management, 90 (2009) 2313-2342.

[5] R. Sabarish, G. Unnikrishnan, Polyvinyl alcohol/carboxymethyl cellulose/ZSM-5 zeolite biocomposite membranes for dye adsorption applications, Carbohydrate Polymers, 199 (2018) 129140. 
[6] R. Sabarish, G. Unnikrishnan, PVA/PDADMAC/ZSM-5 zeolite hybrid matrix membranes for dye adsorption: Fabrication, characterization, adsorption, kinetics and antimicrobial properties, Journal of Environmental Chemical Engineering, 6 (2018) 3860-3873.

[7] E. Forgacs, T. Cserháti, G. Oros, Removal of synthetic dyes from wastewaters: a review, Environment International, 30 (2004) 953-971.

[8] H. Ali, Biodegradation of Synthetic Dyes-A Review, Water, Air, \& Soil Pollution, 213 (2010) 251273.

[9] S. Radoor, J. Karayil, J. Parameswaranpillai, S. Siengchin, Adsorption Study of Anionic Dye, Eriochrome Black T from Aqueous Medium Using Polyvinyl Alcohol/Starch/ZSM-5 Zeolite Membrane, Journal of Polymers and the Environment, 28 (2020) 2631-2643.

[10] S. Mahdavi, M. Jalali, A. Afkhami, Removal of heavy metals from aqueous solutions using Fe304, ZnO, and CuO nanoparticles, in: Nanotechnology for Sustainable Development, 2012, pp. 171-188. [11] A.G. El-Shamy, An efficient removal of methylene blue dye by adsorption onto carbon dot @ zinc peroxide embedded poly vinyl alcohol (PVA/CZnO2) nano-composite: A novel Reusable adsorbent, Polymer, 202 (2020).

[12] K.-T. Chung, Azo dyes and human health: A review, Journal of Environmental Science and Health, Part C, 34 (2016) 233-261.

[13] S. Mani, P. Chowdhary, R.N. Bharagava, Textile Wastewater Dyes: Toxicity Profile and Treatment Approaches, in: Emerging and Eco-Friendly Approaches for Waste Management, 2019, pp. 219-244. [14] M. Rafatullah, O. Sulaiman, R. Hashim, A. Ahmad, Adsorption of methylene blue on low-cost adsorbents: A review, Journal of Hazardous Materials, 177 (2010) 70-80.

[15] L. Shi, L. Hu, J. Zheng, M. Zhang, J. Xu, Adsorptive Removal of Methylene Blue from Aqueous Solution using a Ni-Metal Organic Framework Material, Journal of Dispersion Science and Technology, 37 (2015) 1226-1231.

[16] A. Kumar, H.M. Jena, Removal of methylene blue and phenol onto prepared activated carbon from Fox nutshell by chemical activation in batch and fixed-bed column, Journal of Cleaner Production, 137 (2016) 1246-1259.

[17] S. Kumari, G.S. Chauhan, J.H. Ahn, Novel cellulose nanowhiskers-based polyurethane foam for rapid and persistent removal of methylene blue from its aqueous solutions, Chemical Engineering Journal, 304 (2016) 728-736.

[18] N. Mallick, BioMetals, 15 (2002) 377-390.

[19] M. Bayat, V. Javanbakht, J. Esmaili, Synthesis of zeolite/nickel ferrite/sodium alginate bionanocomposite via a co-precipitation technique for efficient removal of water-soluble methylene blue dye, International Journal of Biological Macromolecules, 116 (2018) 607-619.

[20] E. Alver, A.Ü. Metin, Anionic dye removal from aqueous solutions using modified zeolite: Adsorption kinetics and isotherm studies, Chemical Engineering Journal, 200-202 (2012) 59-67. [21] M. Anbia, S. Salehi, Removal of acid dyes from aqueous media by adsorption onto aminofunctionalized nanoporous silica SBA-3, Dyes and Pigments, 94 (2012) 1-9.

[22] G.V. Brião, S.L. Jahn, E.L. Foletto, G.L. Dotto, Adsorption of crystal violet dye onto a mesoporous ZSM- 5 zeolite synthetized using chitin as template, Journal of Colloid and Interface Science, 508 (2017) 313-322.

[23] H. Aysan, S. Edebali, C. Ozdemir, M. Celik Karakaya, N. Karakaya, Use of chabazite, a naturally abundant zeolite, for the investigation of the adsorption kinetics and mechanism of methylene blue dye, Microporous and Mesoporous Materials, 235 (2016) 78-86.

[24] A.H. Jawad, A.S. Abdulhameed, Mesoporous Iraqi red kaolin clay as an efficient adsorbent for methylene blue dye: Adsorption kinetic, isotherm and mechanism study, Surfaces and Interfaces, 18 (2020).

[25] I. Chaari, E. Fakhfakh, M. Medhioub, F. Jamoussi, Comparative study on adsorption of cationic and anionic dyes by smectite rich natural clays, Journal of Molecular Structure, 1179 (2019) 672-677. 
[26] B.K. Preetha, B. Vishalakshi, Microwave assisted synthesis of karaya gum based montmorillonite nanocomposite: Characterisation, swelling and dye adsorption studies, International Journal of Biological Macromolecules, 154 (2020) 739-750.

[27] M.A. Ahmad, M.A. Eusoff, P.O. Oladoye, K.A. Adegoke, O.S. Bello, Statistical optimization of Remazol Brilliant Blue $\mathrm{R}$ dye adsorption onto activated carbon prepared from pomegranate fruit peel, Chemical Data Collections, 28 (2020).

[28] N.M. Mahmoodi, M. Taghizadeh, A. Taghizadeh, Mesoporous activated carbons of low-cost agricultural bio-wastes with high adsorption capacity: Preparation and artificial neural network modeling of dye removal from single and multicomponent (binary and ternary) systems, Journal of Molecular Liquids, 269 (2018) 217-228.

[29] C. Yin, J. He, S. Liu, Synthesis of mesoporous silicalite-1 zeolite for the vapor phase Beckmann rearrangement of cyclohexanone oxime, Microporous and Mesoporous Materials, 307 (2020). [30] J. Yang, Y.-X. Huang, Y. Pan, J.-X. Mi, Green synthesis and characterization of zeolite silicalite-1 from recycled mother liquor, Microporous and Mesoporous Materials, 303 (2020).

[31] Y.Q. Jing, Y.C. Wang, Y.Z. Gao, H.Q. Li, Y.Y. Cheng, P. Lu, Y.H. Zhang, C. Ma, Synthesis of TiO2loaded silicate-1 monoliths and their application for degradation rhodamine B, RSC Advances, 6 (2016) 42495-42501.

[32] Z.-L. Cheng, Y.-x. Li, Z. Liu, Fabrication of graphene oxide/silicalite-1 composites with hierarchical porous structure and investigation on their adsorption performance for rhodamine $B$, Journal of Industrial and Engineering Chemistry, 55 (2017) 234-243.

[33] R. Sabarish, G. Unnikrishnan, Novel biopolymer templated hierarchical silicalite-1 as an adsorbent for the removal of rhodamine B, Journal of Molecular Liquids, 272 (2018) 919-929.

[34] R. Sabarish, G. Unnikrishnan, Synthesis, characterization and catalytic activity of hierarchical ZSM-5 templated by carboxymethyl cellulose, Powder Technology, 320 (2017) 412-419.

[35] R. Sabarish, G. Unnikrishnan, Synthesis, characterization and evaluations of micro/mesoporous ZSM-5 zeolite using starch as bio template, SN Applied Sciences, 1 (2019).

[36] T. Huang, M. Yan, K. He, Z. Huang, G. Zeng, A. Chen, M. Peng, H. Li, L. Yuan, G. Chen, Efficient removal of methylene blue from aqueous solutions using magnetic graphene oxide modified zeolite, Journal of Colloid and Interface Science, 543 (2019) 43-51.

[37] R. Ling, W. Chen, J. Hou, Preparation of modified MFI (ZSM-5 and silicalite-1) zeolites for potassium extraction from seawater, Particuology, 36 (2018) 190-192.

[38] H. Yang, P. Yang, X. Liu, Y. Wang, Space-confined synthesis of zeolite Beta microspheres via steam-assisted crystallization, Chemical Engineering Journal, 299 (2016) 112-119.

[39] B. Wang, T. Guo, Y. Zhang, F. Chen, P. Rui, X. Xie, W. Liao, Y. Luo, X. Shu, Cobalt oxide encapsulated hydrophilic hierarchical Silicalite-1 for highly efficient conversion of cyclohexyl hydroperoxide, Microporous and Mesoporous Materials, 302 (2020).

[40] O. Duman, T.G. Polat, C.Ö. Diker, S. Tunç, Agar/k-carrageenan composite hydrogel adsorbent for the removal of Methylene Blue from water, International Journal of Biological Macromolecules, 160 (2020) 823-835.

[41] Y. Dong, B. Lu, S. Zang, J. Zhao, X. Wang, Q. Cai, Removal of methylene blue from coloured effluents by adsorption onto SBA-15, Journal of Chemical Technology \& Biotechnology, 86 (2011) 616-619.

[42] L. Mouni, L. Belkhiri, J.-C. Bollinger, A. Bouzaza, A. Assadi, A. Tirri, F. Dahmoune, K. Madani, H. Remini, Removal of Methylene Blue from aqueous solutions by adsorption on Kaolin: Kinetic and equilibrium studies, Applied Clay Science, 153 (2018) 38-45.

[43] G. Limousin, J.P. Gaudet, L. Charlet, S. Szenknect, V. Barthès, M. Krimissa, Sorption isotherms: A review on physical bases, modeling and measurement, Applied Geochemistry, 22 (2007) 249-275. [44] Y. Ho, Review of second-order models for adsorption systems, Journal of Hazardous Materials, 136 (2006) 681-689.

[45] D. Mohan, K.P. Singh, G. Singh, K. Kumar, Removal of Dyes from Wastewater Using Flyash, a Low-Cost Adsorbent ${ }^{\dagger}$, Industrial \& Engineering Chemistry Research, 41 (2002) 3688-3695. 
[46] A. Afkhami, R. Moosavi, Adsorptive removal of Congo red, a carcinogenic textile dye, from aqueous solutions by maghemite nanoparticles, Journal of Hazardous Materials, 174 (2010) 398-403. [47] A.S. Eltaweil, H. Ali Mohamed, E.M. Abd El-Monaem, G.M. El-Subruiti, Mesoporous magnetic biochar composite for enhanced adsorption of malachite green dye: Characterization, adsorption kinetics, thermodynamics and isotherms, Advanced Powder Technology, 31 (2020) 1253-1263. 
Figures<smiles>CN(C)c1ccc2nc3ccc(N(C)C)cc3[s+]c2c1</smiles>

Figure 1

Structural formula of methylene blue
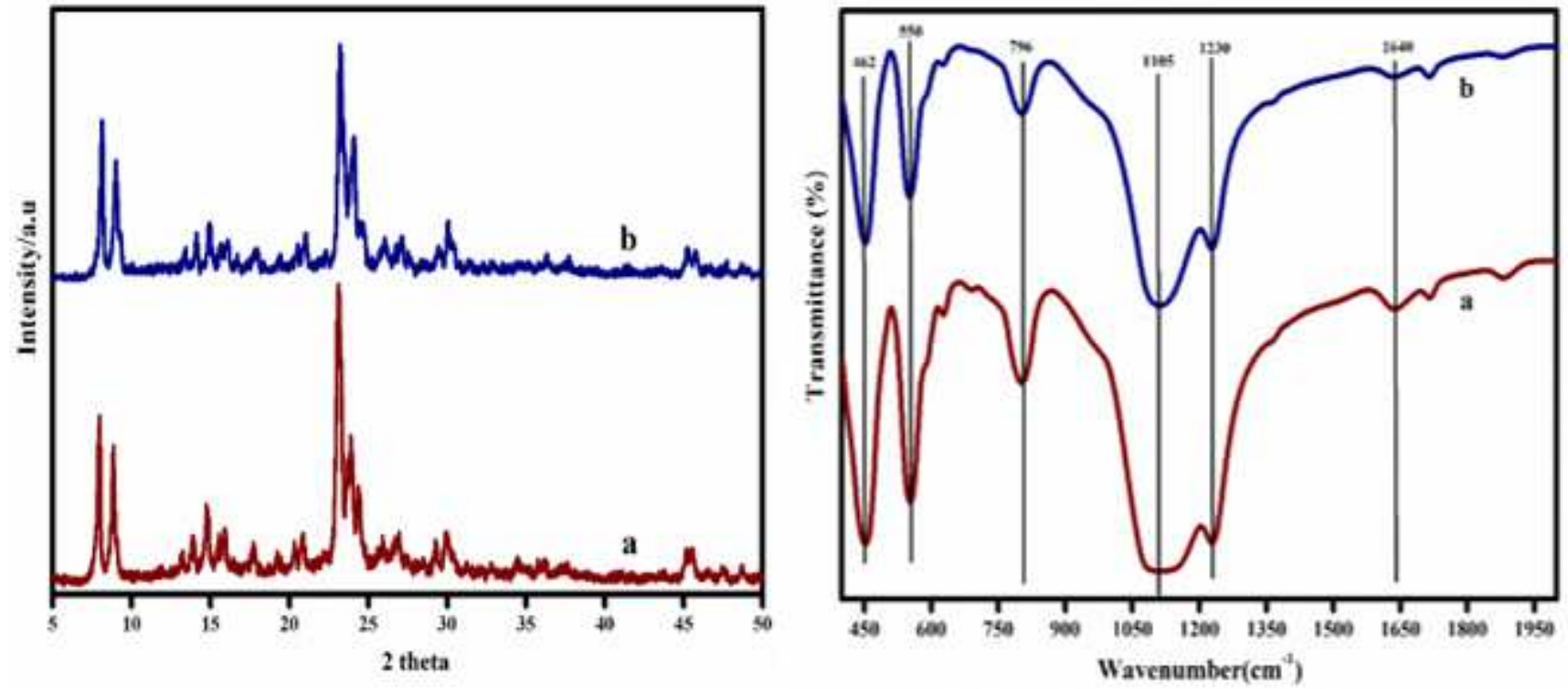

Figure 2

Powder XRD patterns and FTIR spectra of conventional and mesoporous silicalite-1 

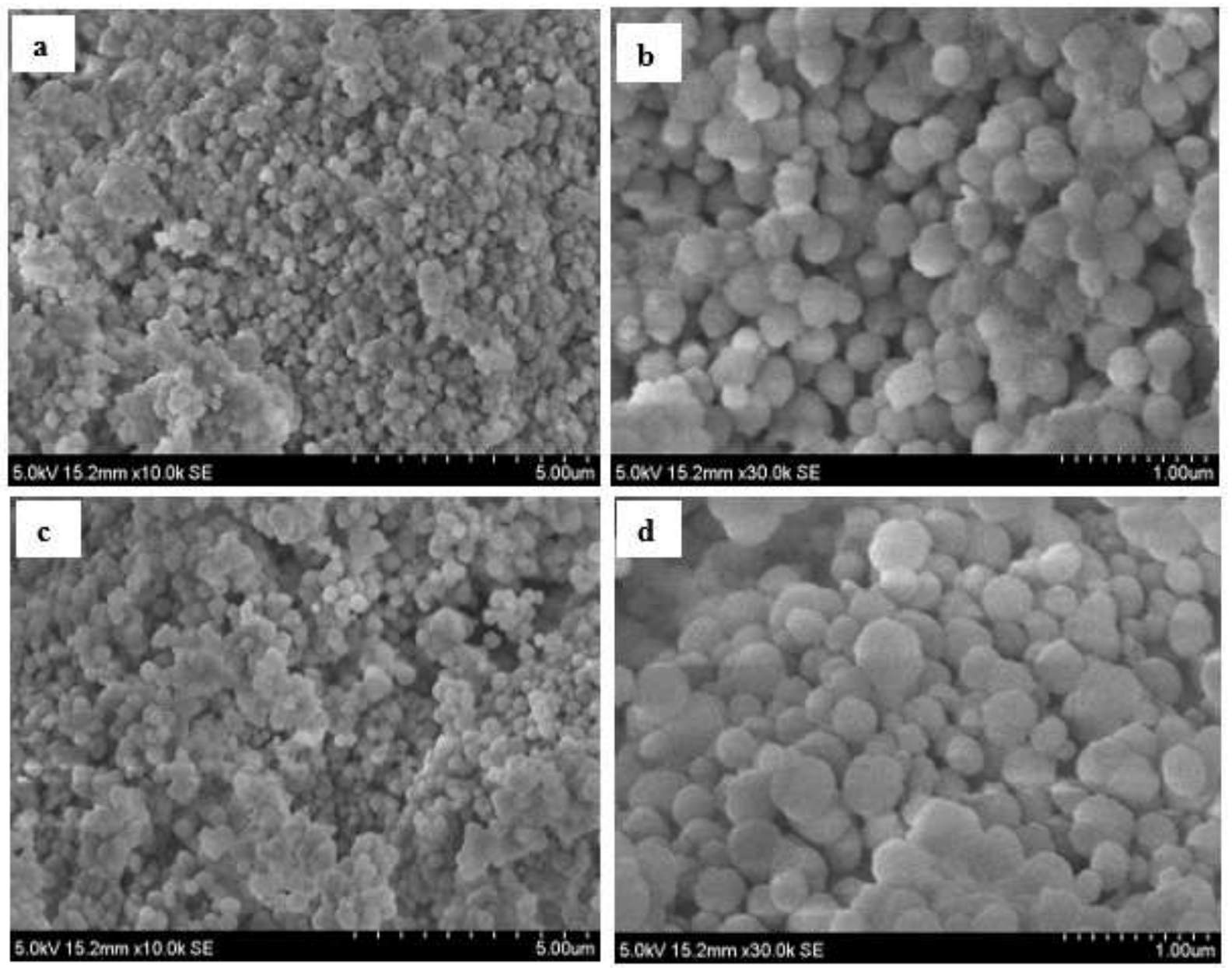

\section{Figure 3}

SEM micrographs of (a \& b) conventional and (c \& d) mesoporous silicalite-1

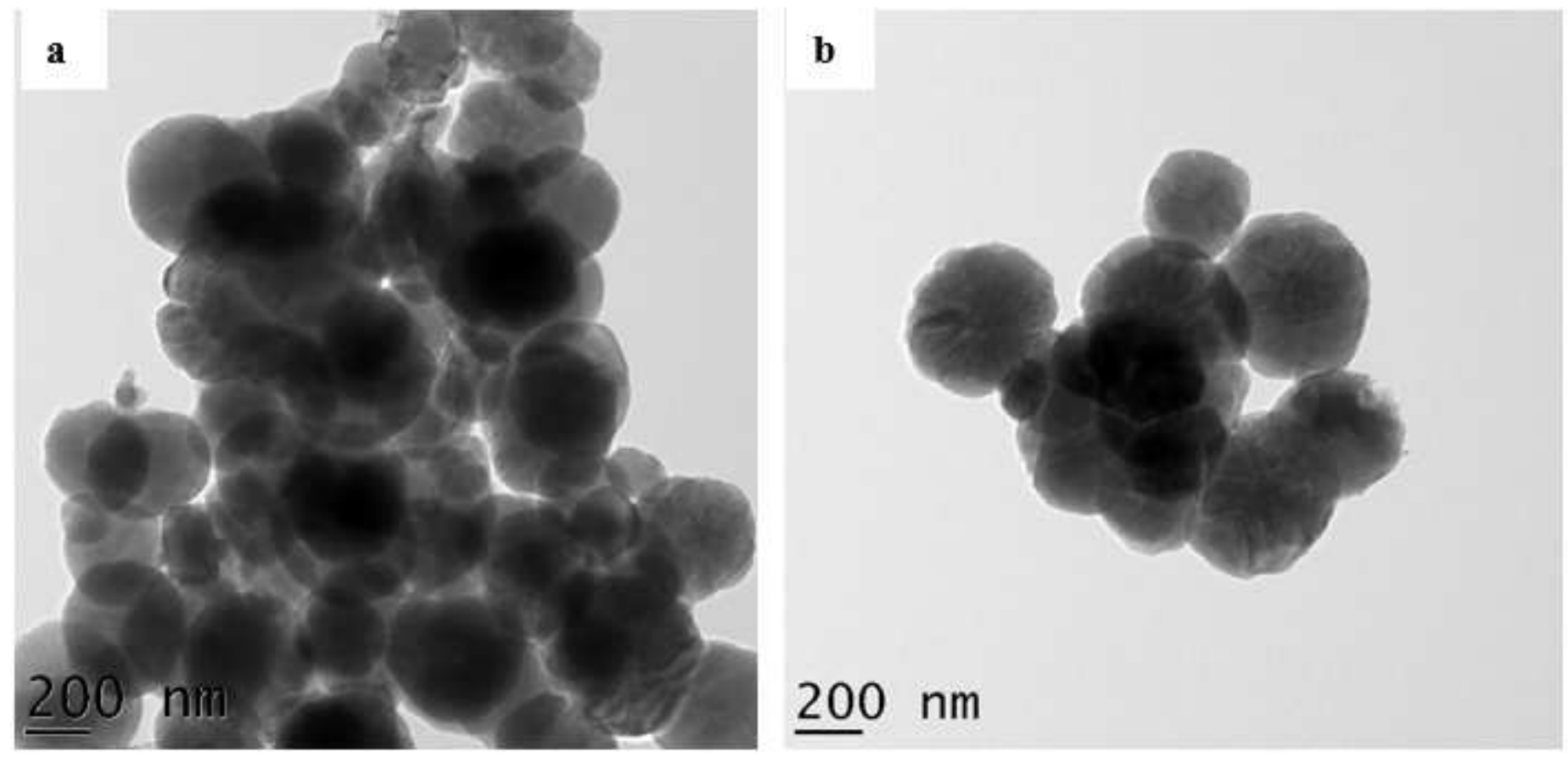


Figure 4

TEM images of mesoporous silicalite-1
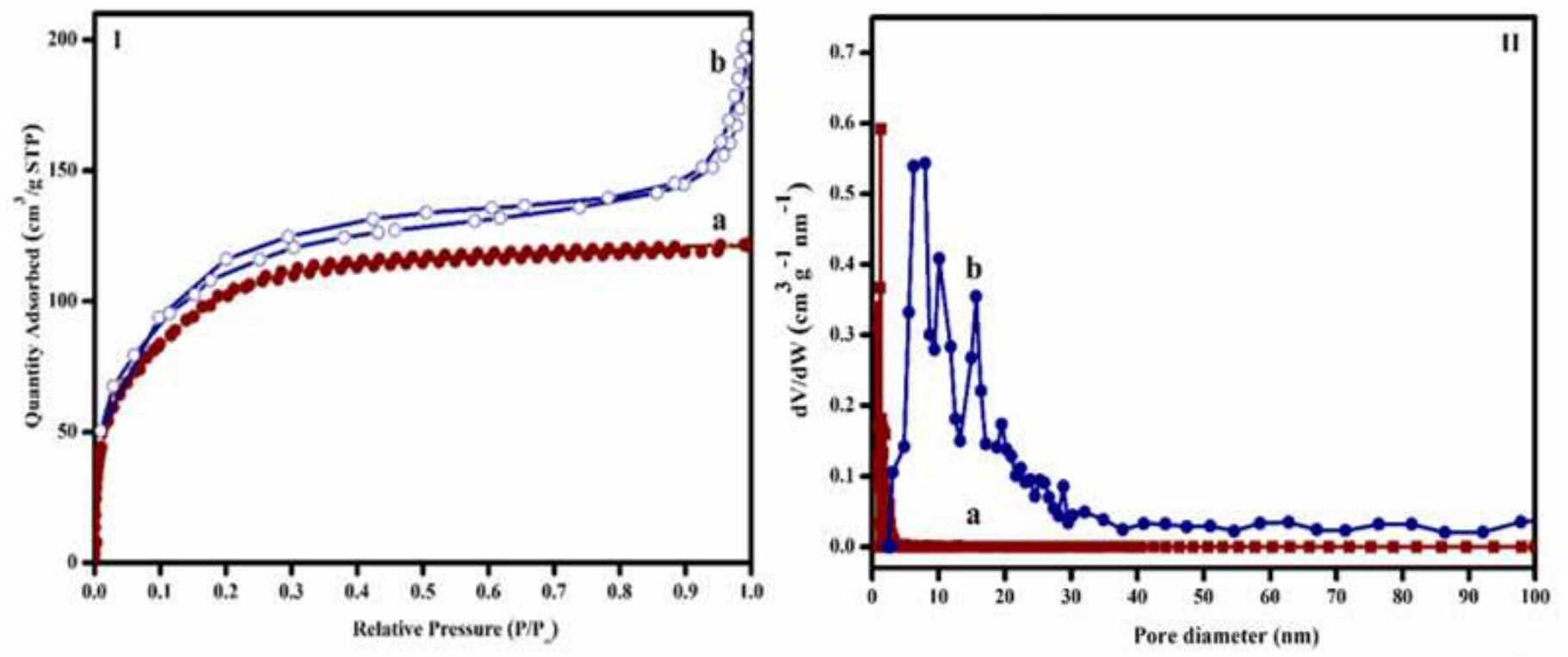

Figure 5

(I) N2 adsorption isotherms of: a) conventional b) mesoporous silicalite-1; (II) pore size distribution of: a) conventional b) mesoporous silicalite-1
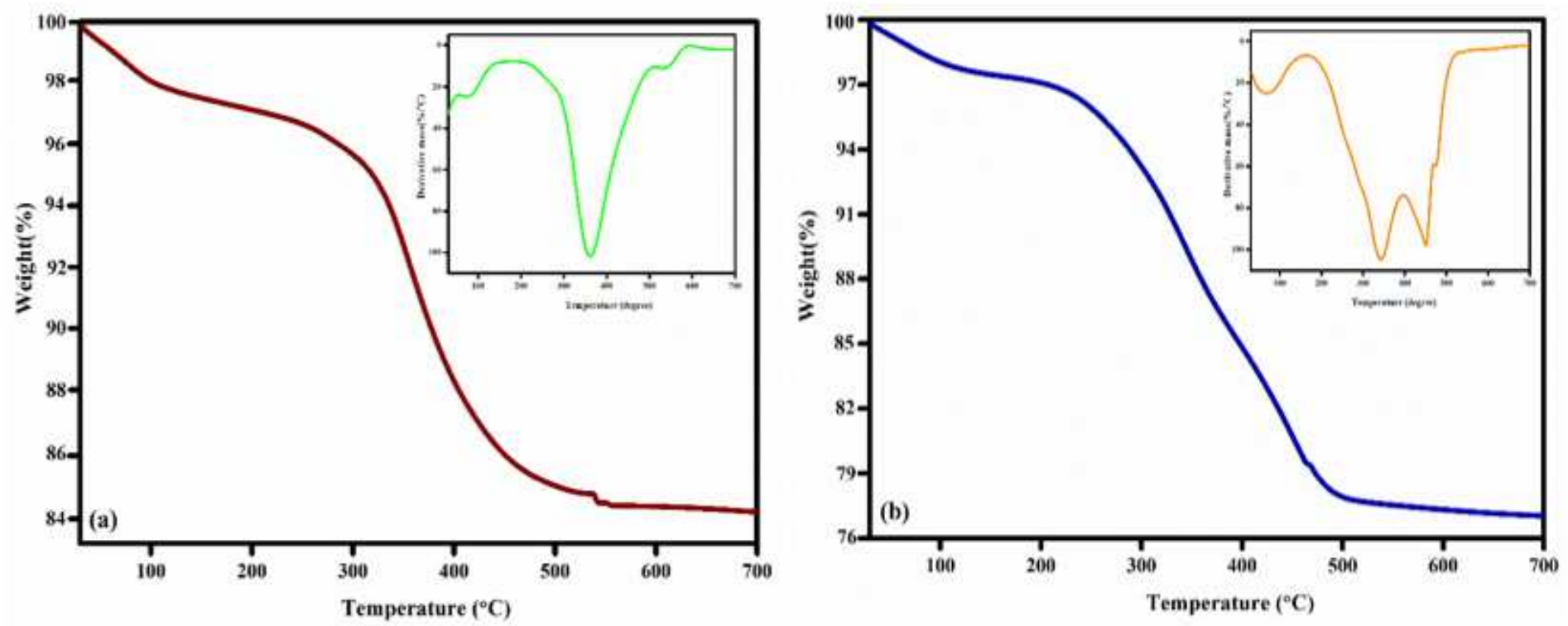

Figure 6

TGA curves of conventional and mesoporous silicalite- 1 and the corresponding DTG curves are given at the inset 


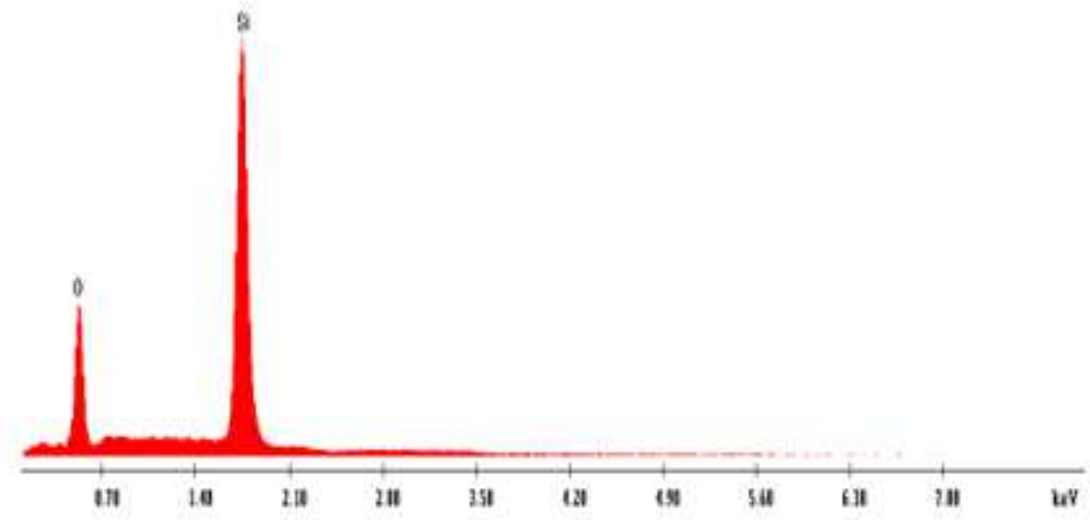

Figure 7

EDS image of mesoporous silicalite-1
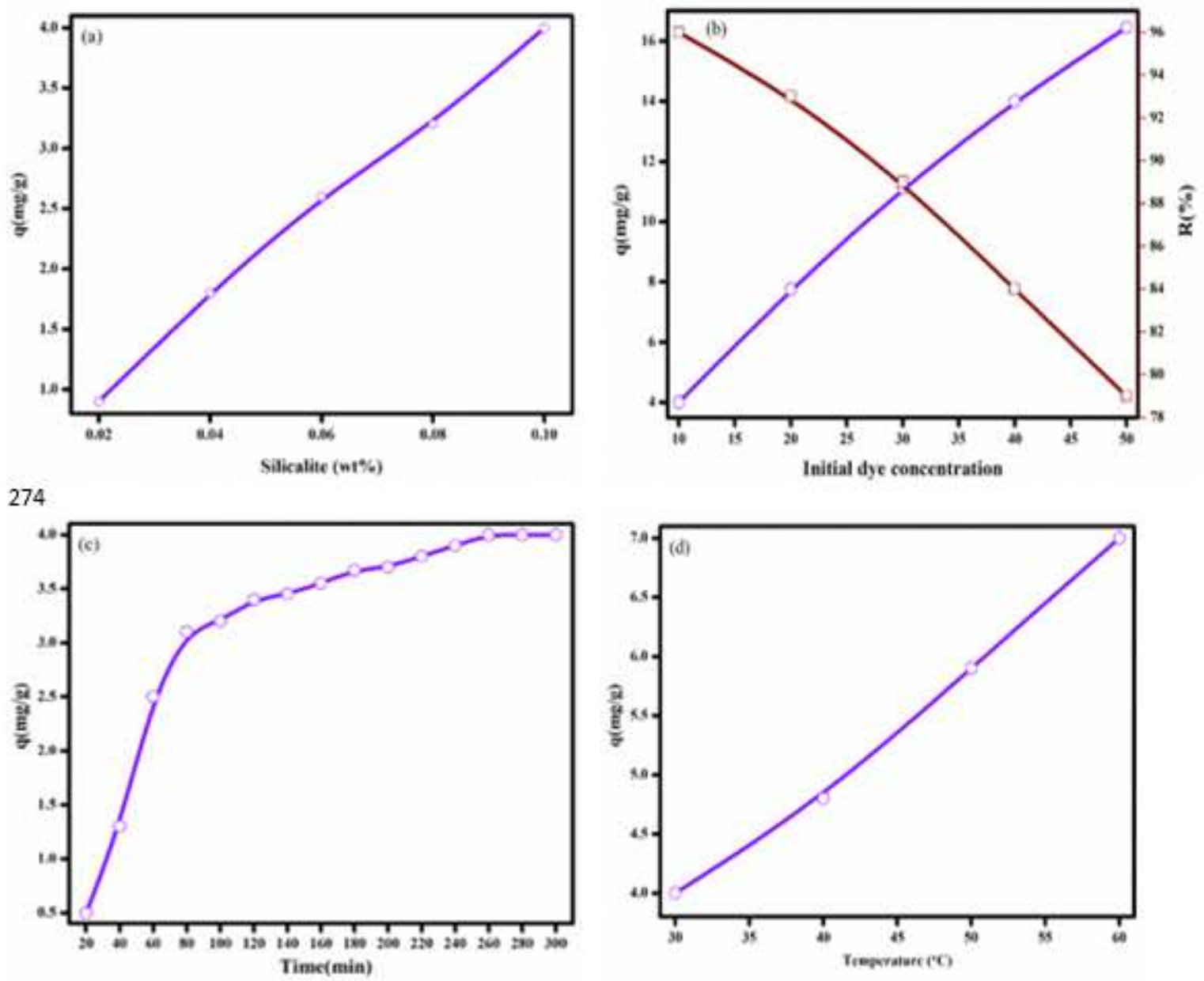

Figure 8

Effect of various parameters on the adsorption of MB onto mesoporous silicalite-1 a) silicalite- 1 dosage b) initial dye concentration c) contact time d) temperature on the adsorption process (adsorbent dosage $=$ $0.10 \mathrm{wt} \%$, initial $\mathrm{MO}$ concentration $=10 \mathrm{ppm}$, contact time $=240 \mathrm{~min}$ and temperature $=30^{\circ} \mathrm{C}$ 

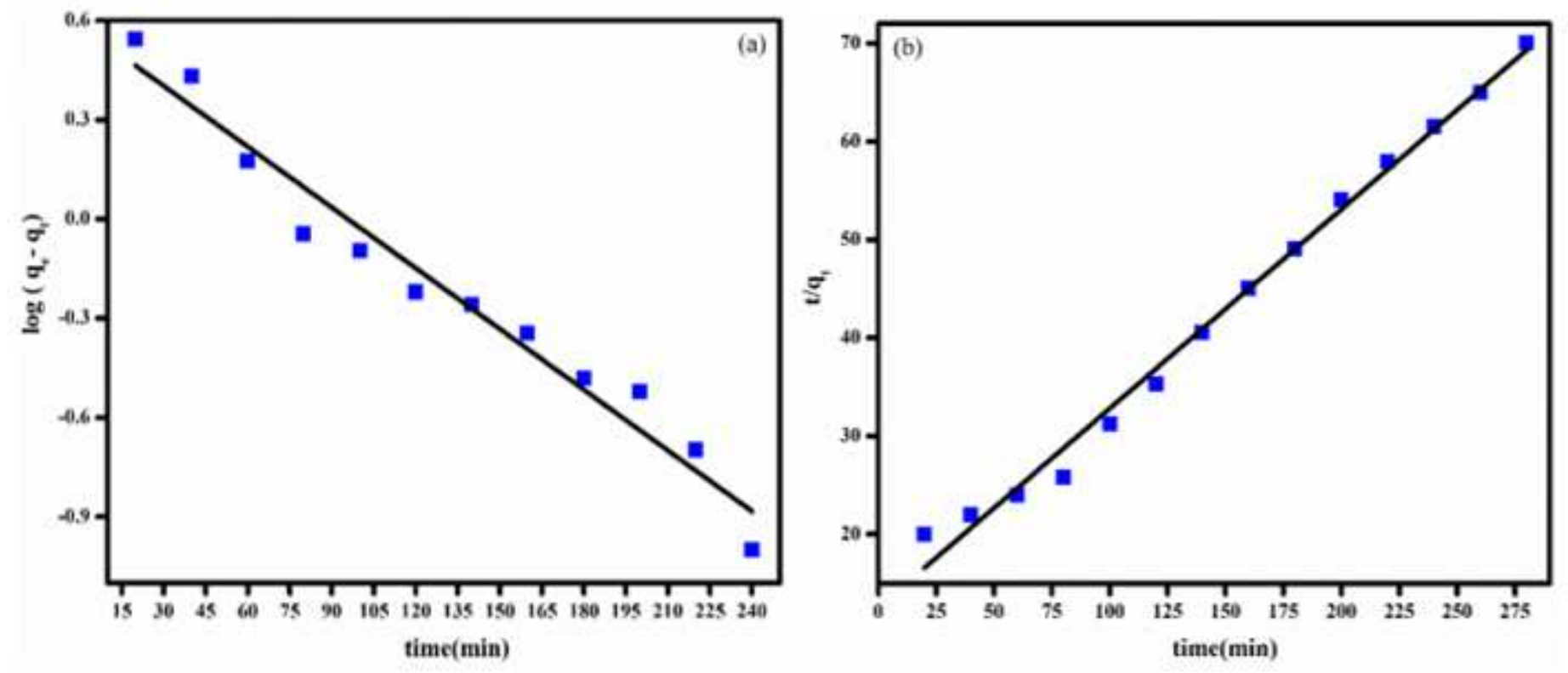

Figure 9

a) pseudo-first-order b) pseudo-second-order models for the adsorption of MB dye onto mesoporous silicalite-1
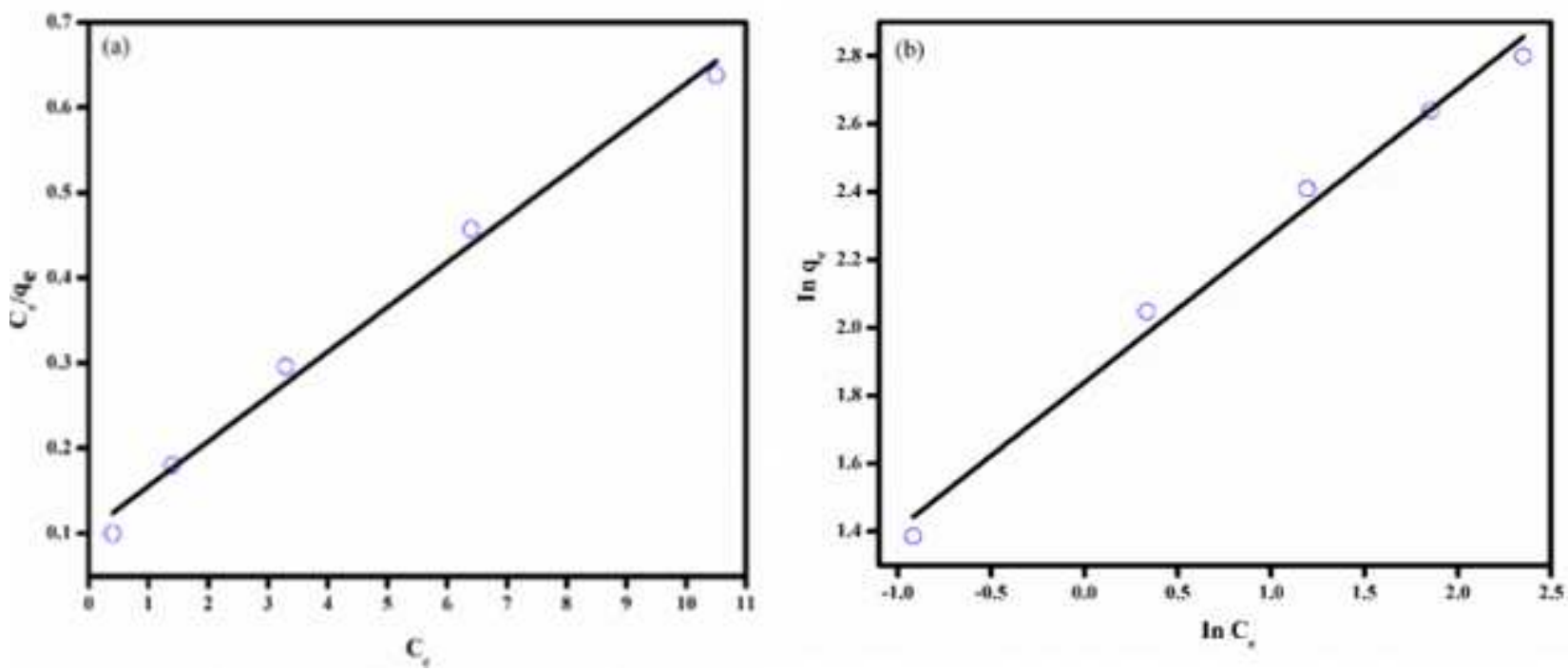

Figure 10

Isotherm model plots for the adsorption of MB a) Langmuir isotherm b) Freundlich isotherm 


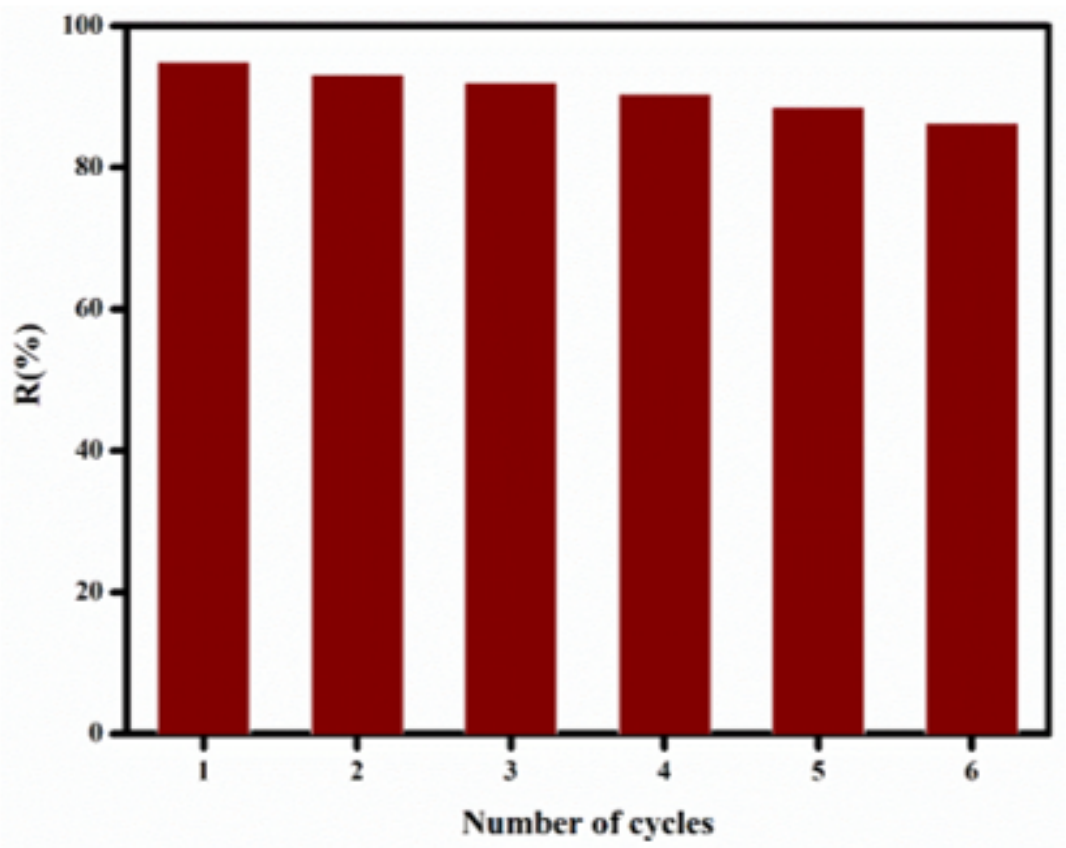

Figure 11

Reusability performance of adsorption of MB onto mesoporous silicalite-1

\section{Supplementary Files}

This is a list of supplementary files associated with this preprint. Click to download.

- Graphicalabstract.docx

- Scheme1and2.docx 